\title{
Tree model with drag, transpiration, shading and deposition: identification of cooling regimes and large-eddy simulation
}

\author{
Tom Grylls ${ }^{\mathrm{a}, *}$, Maarten van Reeuwijk ${ }^{\mathrm{a}}$

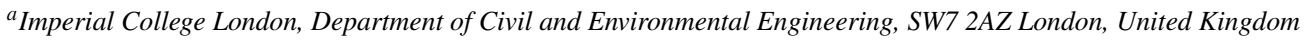

\begin{abstract}
Trees play an important role in the urban heat island effect and urban air quality due to their impact on the transfer of radiation, momentum, heat, moisture and pollution. However, the effects of trees are hard to quantify due to their complex interactions with urban surfaces and the turbulent atmosphere overhead. We present a complete tree model for large-eddy simulations (LES) that represents the effects of trees on drag, transpiration, shading and deposition at resolutions of $\mathrm{O}(1 \mathrm{~m}, 0.1 \mathrm{~s})$ whilst minimising the number of model parameters. The tree model avoids the necessity to resolve the leaf temperature via a derivation of the PenmanMonteith equation and distinguishes between cooling via transpiration and shading. The latent heat flux is further broken down into radiative and advective components in order to better understand the mechanism behind transpirational cooling (e.g. the 'oasis' effect).

The new tree model is investigated analytically to provide insight into tree cooling regimes, and is applied to field studies to contextualise the analysis. The combined cooling effect of trees due to transpiration and shading processes can be reduced to a four-dimensional parameter space. The net tree cooling $(N T C)$ and tree cooling ratio $(T C R)$ parameters are defined to enable a systematic categorisation of the thermal effect of a tree into five regimes: net heating, net reduction (shading dominated), net reduction (transpiration dominated), net cooling (shading dominated) and net cooling (transpiration dominated). Existing parameterisations for tree cooling are reviewed, illustrating their limitations and highlighting the need for complete models to determine tree cooling.

The tree model is implemented into the large-eddy simulation model uDALES. The drag and canopy energy balance models are validated, and results are presented for domains that are 1) fully covered by trees; 2) partially covered by trees; and 3) have a single line of trees. These simulations provide physical insight into the effect of trees on the microclimate and provide evaluation data for future studies.
\end{abstract}

Keywords:

Trees, urban, pollution, shading, transpiration, deposition, cooling regimes, large-eddy simulation

\section{Introduction}

Trees are an integral part of the urban form. By definition, many urban areas are forests and as such the urban canopy layer can be viewed as dichotomous: composed not only of bluff and opaque buildings but also of flexible and permeable trees (where 'forest' implies >10\% tree cover; Grey et al., 1978; Rowntree, 1984; Oke, 1989). The presence of trees in the urban microclimate affects the local exchanges of momentum, radiation, moisture, heat, noise and pollution. Trees can therefore provide many functions, e.g. shade in the summer time, shelter from winter winds, flood risk protection and noise attenuation (Mullaney et al., 2015; Bozovic et al., 2017). They have also been shown

\footnotetext{
${ }^{*}$ Corresponding author

Email address: t.grylls15@imperial .ac .uk (Tom Grylls)
} 
to have both societal and environmental benefits (Willis and Petrokofsky, 2017; Donovan, 2017). However, the roles of trees in mitigating poor urban air quality and the urban heat island (UHI) effect have been more challenging to quantify in comparison to these other benefits. Their complex interactions with the surrounding microclimate mean that there is significant uncertainty surrounding their effects on these two challenges to urban sustainability.

The thermal effects of trees have predominantly been studied with a focus on their potential to act as tools to mitigate the UHI effect (Oke, 1982). The cooling potential of trees can be attributed to two main processes: 1) transpiration that increases the net latent heat flux and reduces the net sensible heat flux over urban areas (the oasis effect, which can be pronounced in urban areas due to the advection of generally warmer and drier air through isolated canopies; Akbari et al., 1990; Grimmond and Oke, 1991); and 2) shading that reduces the net radiative heat incident on surrounding urban surfaces and therefore decreases surface temperatures and heat storage (Oke, 1989; Smithers et al., 2018). Numerous field studies have empirically investigated these cooling effects. However, due to the natural variability and case-specificity of the problem, the magnitude and spatial and temporal extent of this cooling is highly variable across these field studies and it is challenging to attribute cooling to particular processes (Bowler et al., 2010).

In recent years, trees have been incorporated into existing numerical models over a range of scales. A range of modelling approaches have been followed to capture the thermal effects of trees. Often various thermal effects are neglected for simplicity. Yang et al. (2019) review the treatment of trees in both energy balance and computational fluid dynamics (CFD) models and highlight the processes and characteristics (transpiration, radiation transmittance etc.) that are not captured in each of the discussed models. Saaroni et al. (2018) indicate that less than $20 \%$ of the 89 field, experimental and numerical studies on tree's thermal effects that they review directly consider the energy balance of the tree canopy. Tan et al. (2018), Wang et al. (2018) and Rahman et al. (2019) all express the importance of considering both radiative and transpirational effects simultaneously. Specifically, there is a need to be able to attribute cooling between evapotranspirative cooling and shading as that is seen as the key to understanding the differences in tree's cooling potential between species, times of the year, positions and in different climates.

CFD modelling is a key tool in developing our understanding of these thermal effects due to its ability to resolve the unsteady and turbulent urban flow field and to capture horizontal heterogeneity and exchanges that can be challenging to define in mesoscale and energy balance models. The wide range of modelling approaches is particularly evident in the CFD literature. For example, the majority of non-urban studies of tree canopies use a volumetric source of heat to model the divergence of net radiation down through the tree canopy (Shaw and Schumann, 1992). Conversely, Li and Wang (2018) and Salim et al. (2018) neglect the effects of heat exchange within the canopy and consider only the reduced radiative heat flux incident on shaded urban surfaces. In contrast, Gromke et al. (2015) neglect radiative exchanges completely but capture the canopy's bulk transpirational cooling power via a comparison with case-specific field data $\left(P_{c}=250 \mathrm{~W} \mathrm{~m}^{-3}\right)$. This parameterisation has since been used as a benchmark in other studies (Moradpour et al., 2017). These fundamentally different modelling approaches illustrate the necessity to consider energy balances at the scale of interest in order to capture the thermal effects of trees.

Coupled tree and energy balance models have been incorporated into both RANS (Huttner, 2012; Manickathan et al., 2018) and large-eddy simulation (LES) models (Matsuda et al., 2018) to good effect, with the ENVI-Met model most widely used in practice (Tan et al., 2016; Wang and Akbari, 2016; Morakinyo et al., 2017). These studies further illustrate the importance of capturing both radiative and transpirational thermal effects. There are numerous challenges associated with capturing the full complexity of this problem. Introducing a three-dimensional radiative transfer model can significantly increase the computational demands of a model and increases the complexity and degrees of freedom within a given simulation. Resolving the leaf temperature, which has been solved both iteratively and numerically in time in the literature, also increases computational demands and introduces additional free parameters to the problem.

The cooling effect of trees is key to urban design and the sustainability of cities. Yet design guidance is often vague or imprecise which is driven by a lack of understanding of the fundamental parameters that quantify the interaction of trees with the local climate and the inherent case-specificity of the problem (Rahman et al., 2020). A starting point is presented in this study through the identification of cooling regimes for our tree model, which will in time facilitate better designs to optimise the cooling potential of trees.

The effects of trees on pollution dispersion and local air quality can be characterised by the balance between the enhanced rates of deposition (due to their large surface area and surface properties Sæbø et al., 2012) and drag that they impose on the surrounding air (Gromke and Ruck, 2007; Gromke et al., 2008; Gromke and Ruck, 2009; Salim et al., 2015; Buccolieri et al., 2018). Studies have indicated that trees can both help and hinder the local air quality (Jeanjean et al., 2017; Santiago et al., 2017). The review papers of Janhäll (2015), Abhijith et al. (2017) and Buccolieri et al. 
(2018) highlight the need for more air quality studies where tree thermal effects are also considered. The change in energy balances results in a redistribution and change in magnitude of buoyancy sources, and therefore also changes in the dispersion of pollutants local to trees. Considering all of the above, there is a need for a computationally efficient tree model that captures thermal, drag and depositional effects and that can be both investigated analytically and coupled to an LES model.

In this article, a tree model is presented that satisfies these aims. Importantly, it: 1) minimises the number of free parameters that are introduced to an already complex problem and large parameter space; 2) simplifies the problem such that it is analogous to the application of idealised constant surface heat fluxes yet still driven by radiative conditions (a common approach that has been applied in both non-urban and urban contexts; Bertoldi et al., 2013; Boppana et al., 2014; Patton et al., 2016); 3) avoids the need to resolve the leaf temperature; and 4) formulates the thermal effects of the tree such that the contribution of different cooling mechanisms can be quantified. The tree model is therefore capable of capturing the effects necessary to study the role of buoyancy redistribution in pollution dispersion and trees' cooling effects at the microclimate scale. The level of abstraction applied to the tree model is consistent with the simplified approach often applied to the study of non-neutral boundary layers (Bertoldi et al., 2013; Boppana et al., 2014; Patton et al., 2016) and therefore provides a method through which to conduct targeted simulations of urban trees and the capability to isolate particular phenomena. Section 2 describes the formulation of this model and Section 3 expands upon the model formulation to investigate the model analytically and therefore define characteristic dimensionless parameters and regimes for tree cooling. Section 4 introduces the LES model uDALES. Section 5 validates components of the model and also presents further validation cases for future studies. Finally conclusion are drawn in Section 6 and a list of symbols is provided in the Appendix.

\section{Tree model}

The tree model is devised for LES at street-level resolutions. The challenge here is that at $\mathrm{O}(1) \mathrm{m}$ resolutions, trees are resolved partially. This means that the classical mesoscale parameterisations of tree behaviour, in which the tree processes are fully parameterised (see Figure 1c), cannot be used. However, a large part of the tree still needs to be modelled as it is computationally prohibitive and physically undesirable to resolve the entire tree at the microscale (Figure 1a). Thus, borrowing a term from the atmospheric community, there is a need for a 'grey-zone' tree model, in which the tree is partially modelled. The associated scales of tree modelling are shown diagrammatically in Figure 1. In this study, the 'grey-zone' approach is followed.

The formulation of a grey-zone tree model requires a consistent and spatially inhomogeneous representation of the effects of the tree canopy (therefore capable of capturing the intrinsic variability of tree effects in LES). In practice this means representing the drag, thermal, moisture, radiative and deposition processes of the tree canopy as sink/source terms at the designated resolution. The tree canopy is modelled by homogenising its presence within cells of the computational domain such that they have two constituent parts: air and the tree's biomass (the geometry method; Yang et al., 2019). The microscale tree-air interactions as shown in Figure 1a then occur at a sub-grid scale and therefore must be resolved through a set of volumetric source and sink terms $\left(S_{u_{i}}, S_{\varphi}, S_{T}\right.$ and $\left.S_{q}\right)$ that can be applied directly into the right-hand side of the governing equations (see Section 4).

These microscale interactions can be captured at the 'grey-scale' by applying the concept of coarse-graining and parameterising the combined effects of a given surface area of leaves on the corresponding volume of air (depicted in Figure 1b). Specifically, the tree model defines these volumetric terms as functions of the properties of the surrounding air and a set of representative parameters. It is important to note that the parameters must be able to encompass: 1) the natural variability associated with the problem (different species, sizes, ages and meteorological conditions e.g. cloud cover, relative humidity); and 2) be investigated through field and experimental studies such that accurate values can be obtained.

An example of such a parameter is the leaf-area density, $a\left(\mathrm{~m}^{2} \mathrm{~m}^{-3}\right)$, that defines the one-sided surface area of leaves over the volume of air that they are present in. This term acts as an inverse length scale that relates fluxes at the leaf surface (as shown in Figure 1a) to those over the surrounding volume of air (as shown in Figure 1b). It is possible to obtain values for the leaf-area density both experimentally and in the field and this term is capable of capturing both species and seasonal variability (Jeanjean et al., 2017).

The grey-scale spatial resolution of $\mathrm{O}(1 \mathrm{~m})$ permits a reasonable assumption of subgrid homogeneity. For example, for a $1 \mathrm{~m}^{3}$ volume of leaves with a leaf-area density of $1 \mathrm{~m}^{2} \mathrm{~m}^{-3}$ and a leaf size $0.01 \mathrm{~m}^{2}$, there would be 100 leaves 
a)

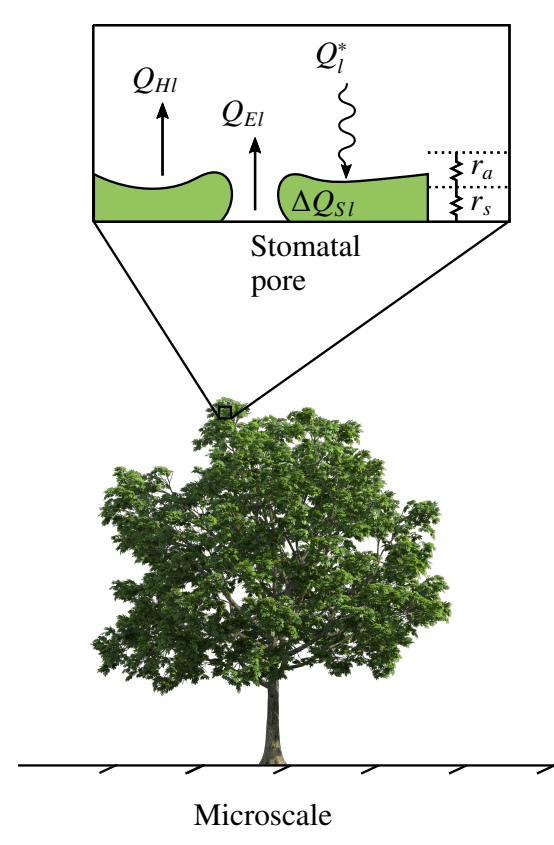

b)

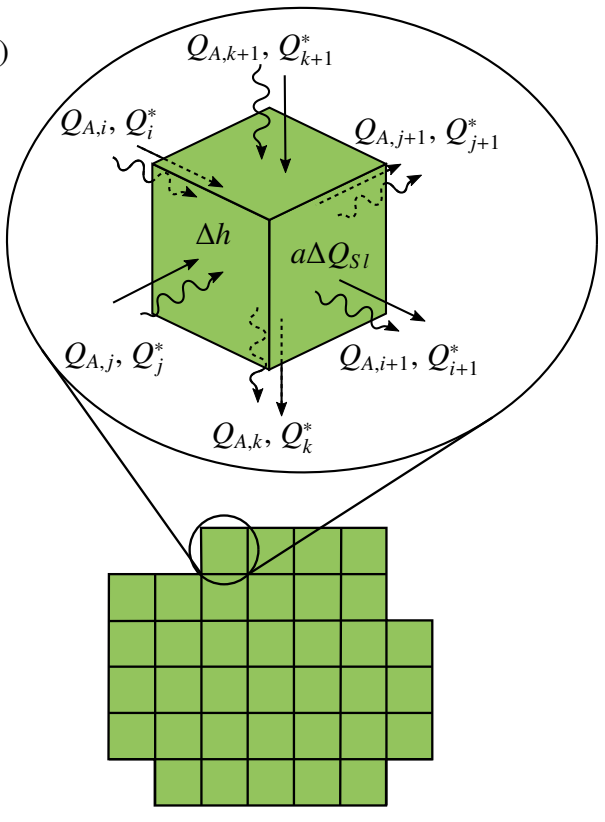

c)

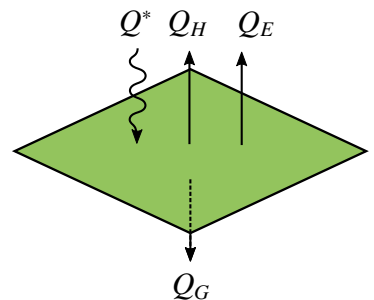

Figure 1. Diagrammatic representation of the different scales of tree modelling. a) Microscale representation with individual leaf energy balances, b) the 'grey-scale' approach followed in this study that parameterises the microscale effects at the resolution of an LES model and c) mesoscale where the effects of individual trees occur at a subgrid scale and the net effects are calculated as a bulk energy balance. 
in the given volume providing a statistically reasonably robust average term for that volume. Simultaneously, the resolution of $\mathrm{O}(1 \mathrm{~m})$ is able to capture spatial inhomogeneity throughout the tree canopy, e.g. leaf-area densities, wind speeds, radiative fluxes and relative humidity.

Therefore, by modelling the sensible and latent heat exchange between the tree canopy and the surrounding air, the tree model described below expands upon the majority of existing tree models in urban CFD that largely focus upon drag and depositional effects under neutral conditions (Moonen et al., 2013; Santiago et al., 2017). Capturing this heat transfer by resolving an energy balance at the 'grey-scale' and therefore modelling the fluxes of both temperature and moisture provides a more complete method in comparison to studies where empirical parameterisations are used (Gromke et al., 2015; Moradpour et al., 2017) or particular phenomena, e.g. transpiration, are neglected (Li and Wang, 2018). Other studies where an energy balance is modelled to capture the thermal effects of trees include the work of Manickathan et al. (2018) and Matsuda et al. (2018). Ensuring that the model is suitable for application within LES means that it must be capable of time resolving the effects of the tree canopy with respect to the turbulent flow field (RANS models parameterise the turbulence to produce steady results). The main simplifications and assumptions applied to form the tree model are: 1) a big-leaf approach (assuming that the values obtained from a given cell are representative of the average conditions of all leaves and that these do not differ at a subgrid scale); 2) simplifying the radiative budget to a one-dimensional problem; and 3) applying a uniform stomatal resistance. The formulation of the source terms is outlined below.

\subsection{Drag}

The volumetric term for drag, $S_{u_{i}}$, is well-established in the literature. Drag is defined as a function of the leaf-area density, local wind velocity and drag coefficient, $C_{d}$. This term captures both the viscous and inertial losses

$$
S_{u_{i}}=-a C_{d}|u| u_{i}
$$

where $a$ is the leaf-area density, $|u|$ is the absolute wind speed and $C_{d}$ is a drag coefficient. Typical values of $a$ range from 0.1-2.0 $\mathrm{m}^{2} \mathrm{~m}^{-3}$ depending on the season, tree species, tree age etc. (Oshio et al., 2015; Jeanjean et al., 2017). Typical values of $C_{d}$ range from 0.1-0.3 depending on the tree species; $C_{d}=0.2$ has been widely applied in the literature for non-species-specific studies (Buccolieri et al., 2018).

Many studies also define additional terms to capture the turbulent kinetic energy (TKE) production and enhanced dissipation resulting from the application of drag to the mean flow (e.g. following the closure scheme of Wilson and Shaw, 1977). Buccolieri et al. (2018) reviews the range of closure schemes and coefficients applied across different studies to capture these effects and evaluates the performance of models with and without these additional terms. Including additional terms in the TKE equation is particularly important for RANS models since these model the entire turbulence spectrum. LES models remain capable of capturing most dynamical scales, and although there are too few studies to conclude whether additional sub-grid scale terms lead to better predictions, LES studies where they are neglected achieve very good agreement with the CODASC wind-tunnel experiments (Moonen et al., 2013). In the approach taken here, we do not include additional terms and empirical coefficients.

\subsection{Deposition}

The volumetric term for deposition, $S_{\varphi}$, adapts the classical approach from mesoscale models (Figure 1c) to a volume of leaves using the leaf-area density (Figure 1b), and is given by

$$
S_{\varphi}=-a u_{d} \varphi
$$

where $u_{d}$ is the deposition velocity and $\varphi$ is the pollution concentration. The deposition velocity is a conductance term that must capture the aerodynamic, laminar boundary layer and surface resistances to pollutant deposition. Values of $u_{d}$ therefore vary significantly between species, pollutants and also due to e.g. ambient humidity and atmospheric stability and there is currently insufficient data to produce a robust parameterisation (Janhäll, 2015). Sæbø et al. (2012) found that $u_{d}$ could vary by 10-20 times depending on the leaf hairiness. Comprehensive studies have been conducted into the magnitude of constant values of $u_{d}$ for different tree species, pollutants and under different conditions (Janhäll, 2015; Santiago et al., 2017). Typical values are less than $0.01 \mathrm{~m} \mathrm{~s}^{-1}$ for most pollutants and tree species. 


\subsection{Canopy energy balance}

In order to effectively capture the thermal effects of trees it is necessary to consider the surrounding energy balance system (both the tree canopy and the surrounding surfaces; Yang et al., 2019). The presence of a tree canopy fundamentally alters the energy balance of the local urban microclimate due to 1) radiative exchanges within the canopy and between the canopy, the sky and the surrounding buildings; and 2) sensible and latent heat exchanges between the tree and the surrounding air.

Figure 1 highlights the relevant energy balances at the different scales of the problem. At the microscale (Figure 1a), one can define a leaf surface energy balance following

$$
c_{p l} \frac{\mathrm{d} T_{l}}{\mathrm{~d} t}=Q_{l}^{*}-Q_{H l}-Q_{E l}
$$

where $c_{p l}$ is the heat capacity of a leaf, $T_{l}$ is the leaf surface temperature and $Q_{l}^{*}, Q_{H l}$ and $Q_{E l}$ are the net radiative, sensible and latent heat fluxes respectively. The subscript, $\cdot_{l}$, signifies values at the leaf surface that are assumed homogeneous at the grey-scale (the big-leaf approach). The second and third terms on the right hand side of Equation 3 define the transfer of energy between the leaf and the surrounding air. Applying the big-leaf approach (Dai et al., 2004) at the 'grey-scale' by integrating over a volume of tree biomass (see Figure 1b), Equation 3 becomes

$$
\frac{\mathrm{d}}{\mathrm{d} t} \int I \mathrm{~d} V=\oint Q^{*} \mathrm{~d} S-\int a Q_{H l} \mathrm{~d} V-\int a Q_{E l} \mathrm{~d} V
$$

where $I$ is the internal energy of the tree biomass and $Q^{*}$ is the net radiative flux defined over the surface of the control volume. The leaf-area density, $a$, translates the sensible and latent heat flux from individual leaf surfaces to a volumetric term. In terms of pollution dispersion and the UHI effect we are primarily interested in how this balance affects the enthalpy of the surrounding air. In the LES domain, cells where the tree canopy is present have two constituent parts: moist air and the tree's biomass. As such we can define a corresponding energy balance for the specific enthalpy of moist air, $h_{v}$, over the same control volume

$$
\frac{\mathrm{d}}{\mathrm{d} t} \int h_{\nu} \mathrm{d} V=\oint Q_{A} \mathrm{~d} S+\int a Q_{H l} \mathrm{~d} V+\int a Q_{E l} \mathrm{~d} V
$$

where $Q_{A}$ is the advective heat flux. Equation 5 is inherently coupled with Equation 4 and summed together these two equations define the 'grey-scale' energy balance as depicted in Figure 1b. The advective term in Equation 5 is captured by construction in the LES model. The specific enthalpy of moist air is a function of both the potential temperature, $\theta$, and water vapour specific humidity, $q_{v}$, which are modelled as prognostic fields in uDALES (see Section 4). Correspondingly, the latent heat flux represents the energy transferred to vaporise liquid water at the leaf surface and results in a source of specific humidity $q_{v}$ in the air

$$
S_{q_{v}}=a \frac{Q_{E l}}{\rho L_{v}}
$$

where $\rho$ is the air density and $L_{v}$ is the latent heat of vaporisation. The sensible heat flux is the energy supplied to heat or cool the surrounding air and therefore can be defined as

$$
S_{T}=a \frac{Q_{H l}}{\rho c_{p}}
$$

where $c_{p}$ is the heat capacity of the air. The tree model must therefore obtain values of $Q_{E l}$ and $Q_{H l}$ following the leaf surface energy balance (Equation 3). Although all four terms in this equation can be defined as a function of the leaf temperature, the methodology pursued in this paper avoids using the leaf temperature altogether (see section 2.3.2).

\subsubsection{Radiative budget}

Short- and long-wave radiation is absorbed, reflected, transmitted and emitted throughout the tree canopy. The radiation budget over a volume of leaves is three-dimensional, involves multiple scattering and is a function of the leaf temperature itself. Matsuda et al. (2018) use the radiosity method to solve a three-dimensional radiative transfer 


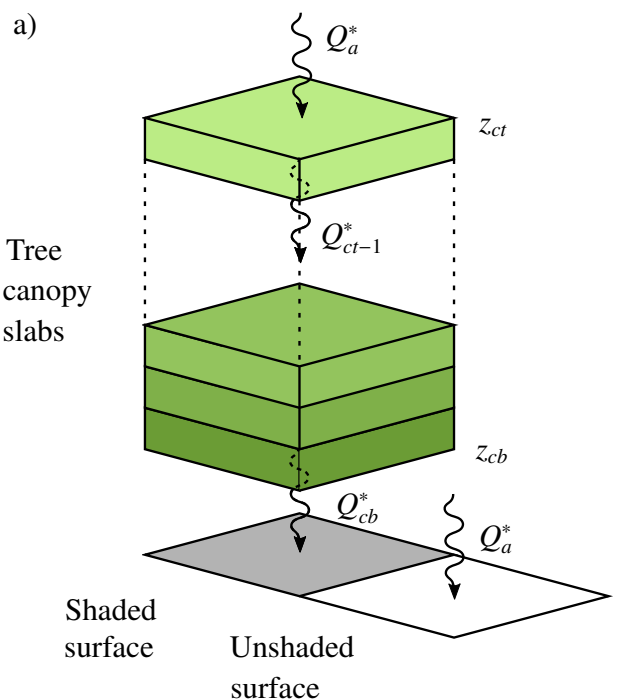

b)

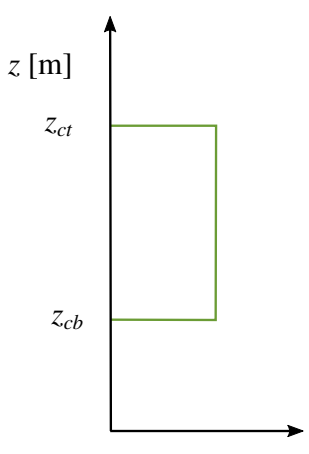

$a$

$\left[\mathrm{m}^{2} \mathrm{~m}^{-3}\right]$ c)

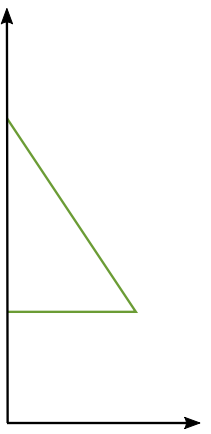

$d$

[-] d)

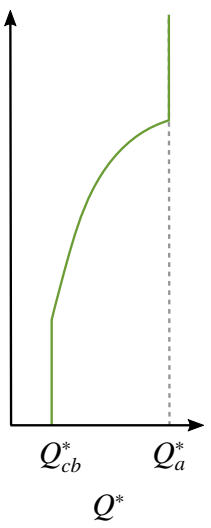

$\left[\mathrm{W} \mathrm{m}^{-2}\right]$

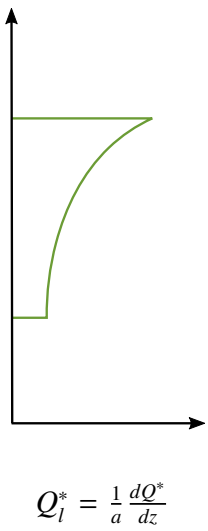

$\left[\mathrm{W} \mathrm{m}^{-2}\right]$

Figure 2. a) Diagrammatic representation of the one-dimensional radiative budget broken down into horizontal slabs at the grey-scale and vertical profiles of b) leaf-area density, c) leaf area index, d) net radiation and e) net radiation incident on the leaf surface.

model. This approach captures complex horizontal exchanges of radiation (e.g. between the adjacent buildings) however it is also computationally intensive and introduces numerous additional free parameters to the problem.

A common simplification when considering the radiative budget of a tree canopy is to reduce it to a one-dimensional problem by assuming relative horizontal homogeneity within the canopy (Monteith and Unsworth, 2013) and that the radiative budget is dominated by the incoming radiation from above (indicative of day-time conditions). This simplification is consistent with the application of constant surface heat fluxes at the road and rooftop levels for unshaded surfaces. Similar assumptions are made in the urban studies of Li and Wang (2018), Manickathan et al. (2018) and the non-urban studies of Patton et al. (2016) and Bertoldi et al. (2013). In the urban context, this requires a 'big-canyon' assumption where sky view factor changes and radiative interactions between the shaded and the unshaded surfaces are neglected. Following this methodology, simulations can be partially driven by the assigned radiative conditions instead of specifying a heat flux a priori. The urban form can be split into unshaded surfaces where the incident net radiative energy is transferred unimpeded and shaded surfaces where the shading effect of the tree results in reduced incoming net radiative energy (see Figure 2). The disadvantage of such a simplification, particularly within urban morphologies, is the inherent heterogeneity of tree and building forms.

Above the shaded surfaces, the tree canopy is simplified to a series of horizontal slabs where the incoming radiative flux from above is larger than the outgoing flux to the layer below. The attenuation of radiation through the tree canopy is a function of e.g. the leaf orientation, albedo, transmissivity and emissivity. An established method to simplify the radiative exchange through the tree canopy is the application of the Beer-Lambert law that relates the attenuation of radiative fluxes to the properties of the medium through which it is travelling (Brown and Covey, 1966; Shaw and Schumann, 1992)

$$
Q^{*}(z)=Q_{a}^{*} e^{-\alpha d(z)}
$$

where $Q_{a}^{*}$ is the net radiation above the urban area, $\alpha$ is the extinction coefficient and $d$ is the cumulative leaf area index defined as $d(z)=\int_{z}^{z c b} a\left(z^{\prime}\right) d z^{\prime}$. This equation relates the attenuation of radiation through the tree canopy to the properties of the canopy itself. The attenuation coefficient is the product of the cumulative leaf area index and the extinction coefficient. The extinction coefficient is therefore a dimensionless parameter that captures the multiplescattering and absorption of radiation within the canopy (as a function of the leaf albedo, emissivity, transmissivity and orientation).

Equation 8 can be applied to horizontal slabs at the grey-scale (as shown in Figure 2a) to obtain the net radiation at intervals throughout the tree canopy or to obtain bulk values across the canopy as is done in Section 3 . Figure 2 
displays example profiles of the leaf-area density $a$, leaf area index $d$, net radiation $Q^{*}$ for a canopy with constant $a$.

Analysis of the performance of Equation 8 against more complex multiple-scattering radiative approaches (Zhao and Qualls, 2005, 2006) was performed in Grylls (2020). It was shown that the application of the Beer-Lambert law for both direct and diffuse shortwave and longwave radiation (all with the same extinction coefficient) in the tree model leads to an overestimation in decay. The extinction coefficient must also capture the scattering process and therefore a lower than average value of 0.4 is suggested. The net radiation above the urban area $Q_{a}^{*}$ is defined following established mesoscale parameterisations (defined as a function of the time of day, day of year, cloud cover, surface albedo and surface emissivity; Kasten and Czeplak, 1980; Holtslag and Nieuwstadt, 1986). Here we use the parameterisations used in the operational pollution dispersion model, SIRANE (Soulhac et al., 2011), in turn based of the approach taken in ADMS (McHugh et al., 1997).

The relation between the net radiation at the leaf $Q_{l}^{*}$ captured at the grey-scale and the net radiation $Q^{*}$ is given by

$$
Q_{l}^{*}(z)=\frac{1}{a} \frac{d Q^{*}}{d z} .
$$

Substitution of Equation 8 into the equation above results in $Q_{l}^{*}(z)=\alpha Q^{*}(z)$. Figure 2e shows the profile of the net radiation at the leaf $Q_{l}^{*}$ for the example canopy, and indicates how leaves at the top of the tree receive the largest net radiative flux.

\subsubsection{Canopy heat storage}

The heat storage term in Equation 4 encompasses both the change in internal energy of the tree canopy and the photosynthetic heat component. The thermal properties of trees and the ability to regulate leaf temperatures via transpiration mean that in comparison to the other materials found in urban areas, a tree's thermal inertia and therefore storage term is relatively low (the photosynthetic component is generally assumed to be negligible). Oliphant et al. (2004) investigated the heat storage term within deciduous forest canopies and found that generally both the internal energy and photosynthetic storage terms are negligible (maximum 5\% of total storage term inclusive of soil and air in the canopy). Many studies therefore neglect heat storage within the tree canopy completely and the same simplification is applied in the tree model presented here, i.e. $\Delta Q_{S l}=0$ (Manickathan et al., 2018).

\subsubsection{Latent and sensible heat fluxes}

From Equations 6 and 7, it is shown that it is necessary to obtain values for $Q_{E l}$ and $Q_{H l}$ terms at the grey-scale in order to obtain the volumetric source/sink terms to be applied in LES $\left(S_{q_{v}}\right.$ and $\left.S_{T}\right)$. The leaf sensible and latent heat fluxes within the tree canopy must therefore be modelled.

In absence of thermal storage, the net radiation on the leaf surface, $Q_{l}^{*}$, quantifies the available energy for sensible $\left(Q_{H l}\right)$ and latent $\left(Q_{E l}\right)$ heat exchange between the leaves and the surrounding air. Rearranging Equation 3 gives

$$
Q_{l}^{*}=Q_{H l}+Q_{E l}
$$

and therefore if one of the terms on the right hand side can be calculated, the leaf energy balance can be closed. Figure 1a shows this relationship diagrammatically and also highlights the aerodynamic resistance, $r_{a}$, and stomatal resistance, $r_{s}$, which can be used to define the heat and water vapour transfer coefficients. The aerodynamic resistance $r_{a}$ captures the resistance to turbulent exchange within the leaf's boundary layer and can be approximated by (Thom, 1968; Dauzat et al., 2001)

$$
r_{a}=C\left(\frac{l}{\left|u_{i}\right|}\right)^{1 / 2}
$$

where $l$ is the leaf size, $|u|$ is the wind speed and $C$ is a proportionality coefficient (Parlange and Waggoner (1972) empirically defined $C \approx 130 \mathrm{~s}^{1 / 2} \mathrm{~m}^{-1}$ by studying leaves in a wind-tunnel). The stomatal resistance $r_{s}$ captures the regulatory control exhibited by the leaf on the size of the stomatal openings. The stomata are pores that facilitate gas exchange and as such determine the rate of transpiration from the leaves of the tree. There are numerous parameterisations of the stomatal resistance as reviewed by Damour et al. (2010) that aim to capture the physiological processes occurring within the tree (soil water availability, temperature, shortwave irradiation, $\mathrm{CO}_{2}$ concentration etc.). For simplicity, uniform values of stomatal resistance are applied in this study. For deciduous trees the minimum stomatal 
resistance $r_{s}$ is in the range 150-450 s m${ }^{-1}$ (Jones, 2013). The sensible and latent heat fluxes between the leaf and surrounding air then follow (Manickathan et al., 2018)

$$
\begin{aligned}
Q_{H l} & =\frac{2}{r_{a}} \rho c_{p}\left(T_{l}-T\right) \\
Q_{E l} & =\frac{1}{r_{a}+r_{s}} \frac{\rho R_{a} L_{v}}{p_{0} R_{v}}\left(\varepsilon_{v l}-\varepsilon_{v}\right)
\end{aligned}
$$

where the right-hand sides of the equations are composed of resistance terms for the pathway between the leaf surface and bulk air, unit conversion terms ( $\rho$ is the density of air, $c_{p}$ is the heat capacity of the air, $R_{a}$ and $R_{v}$ are the gas constants of dry air and water vapour respectively, $p_{0}$ is the atmospheric pressure and $L_{v}$ is the latent heat of vaporisation), $\varepsilon_{v l}$ is the vapour pressure at the leaf surface $(\mathrm{Pa}), \varepsilon_{v}$ is the vapour pressure of the surrounding air (Pa), $T_{l}$ is the temperature of the leaf and $T$ is the temperature of the surrounding air. The factor 2 in Equation 12 is due to the definition of the leaf-area density as the one-sided area (most leaves are hypostomatous meaning that stomata are situated on the underside of the leaf only whereas sensible heat exchange occurs on both sides of the leaves). Classically, the vapour pressure at the leaf surface is assumed to equal the saturation vapour pressure at the temperature of the leaf surface, i.e. $\varepsilon_{v l} \equiv \varepsilon_{s}\left(T_{l}\right)$ (Robitu et al., 2006). Both the sensible and latent heat fluxes are therefore a function of the leaf temperature.

A unique feature of the tree model presented here is that it avoids the necessity to model the leaf temperature. This can be achieved by following the derivation of the classical Penman-Monteith equation which employs a Taylor series expansion of the saturation pressure around the atmospheric temperature. Equation 13 can be substituted into Equation 3 by partitioning the vapour pressure difference between the leaf surface and the surrounding air to the vapour pressure deficit of the surrounding air, $D=\varepsilon_{s}(T)-\varepsilon_{v}$, and a term that is proportional to the temperature difference between the leaf surface and the surrounding atmosphere $s\left(T_{l}-T\right)$ (where $s$ is the slope of the curve relating saturation pressure to temperature; Jones, 2013). The sensible heat flux can be substituted into this equation and this term can then be substituted into the energy balance for the leaf, resulting in (see Appendix A for a complete derivation):

$$
Q_{E l}=\underbrace{\omega_{l} Q_{l}^{*}}_{Q_{E l, r}}+\underbrace{\omega_{l} \frac{2 \rho c_{p} D}{s r_{a}}}_{Q_{E l, o}}
$$

where

$$
\omega_{l}=\left(1+\frac{2 \gamma}{s} \frac{r_{a}+r_{s}}{r_{a}}\right)^{-1} .
$$

Here, $\gamma=p_{0} c_{p} R_{v} /\left(R_{a} L_{v}\right)$ is the psychometric constant. The dimensionless decoupling factor $\omega_{l}$ is a function of the relative magnitudes of the stomatal and aerodynamic resistances and therefore changes depending on the relative significance of atmospheric versus surface processes (Oke et al., 2017). McNaughton and Jarvis (1983) rearranged the classical Penman-Monteith equation to define a decoupling factor, $\Omega=1 /\left[1+\left(2 \gamma r_{s}\right) /\left(r_{a}(s+2 \gamma)\right)\right]$, that behaves similarly to $\omega_{l}$ by determining the relative significance of $Q_{l}^{*}$ and $D$ (Pereira, 2004; Machimura et al., 1997). In this study, we choose the dimensionless parameter $\omega_{l}$ over $\Omega$ as it enables the analytical investigation of the tree model in Section 3. Typical bulk values of the decoupling factor of trees indicate that the latent heat flux is primarily driven by its advective component due to their elevated positions and therefore strong coupling to a large proportion of the atmospheric boundary layer (ABL). At the 'grey-scale' this relationship will vary both spatially throughout the tree canopy and in time (see Figure 1; consistent with studies into the decoupling factors variability; Pereira, 2004).

The form of Equation 14 is helpful to understand trees' transpirational cooling potential. The term including $Q_{l}^{*}$ relates to the transpiration that occurs due to the available energy from the net radiation incident on the leaf surface (the radiative component of the latent heat flux $Q_{E l, r}$ ). The term including $D$ defines the transpiration that occurs due to the advection of drier air over the leaf surface (or the 'oasis' effect; the advective component of the latent heat flux $\left.Q_{E l, o}\right)$. Finally, the leaf surface sensible heat flux $Q_{H l}$ can be obtained by rearranging Equation 10, using that $\Delta Q_{S l}=0$ as discussed in Section 2.3.2.

\subsection{Surface energy balance}

The energy balance of the tree canopy is driven partially via the net radiation above the urban surface $Q_{a}^{*}$. The tree model therefore needs to be used in conjunction with a model for the energy balance of the surrounding surfaces, 
which must also capture the shading effect of the tree. The one-dimensional treatment of the radiation budget means that ground- and roof-level surfaces must be considered (see Figure 2). It is therefore necessary to define an urban surface energy balance that estimates the sensible heat flux from the unshaded and shaded urban surfaces driven by $Q_{a}^{*}$ and $Q_{c b}^{*}$ respectively (see Figure 2). Following from the one-dimensional treatment of the radiative budget and assuming the urban surfaces are dry $\left(Q_{E 0}=0\right)$, an energy balance can be defined for the unshaded ground and roof surfaces following

$$
Q_{a}^{*}=Q_{H 0}-\Delta Q_{S 0}
$$

where $Q_{a}^{*}$ is defined following the methodology discussed in Section 2.3.1, $Q_{H 0}$ is the sensible heat flux from the ground- and roof-level surfaces and $\Delta Q_{S 0}$ is the heat storage term of the roads/ buildings.

In order to define a surface temperature flux $\phi_{\theta 0}=Q_{H} /\left(\rho c_{p}\right)$ (in line with the stated aims of this model), the heat storage term for the unshaded surfaces is parameterised as a function of the net radiation above the urban area following the Objective Hysteresis Model (OHM; Grimmond and Oke, 1999, 2002)

$$
\Delta Q_{S 0}=A_{1} Q_{a}^{*}+A_{2} \frac{\partial Q_{a}^{*}}{\partial t}+A_{3}
$$

where $A_{1}, A_{2}$ and $A_{3}$ are constants that can be defined empirically or analytically following Sun et al. (2017). In this study, average empirical values for paved/ impervious surfaces are used $\left(A_{1}=0.70, A_{2}=0.33 \mathrm{~h}\right.$ and $A_{3}=-38 \mathrm{~W}$ $\mathrm{m}^{-2}$ ). At the shaded surfaces the net radiative flux in Equation 16 is the net radiation at the base of the tree canopy $Q_{c b}^{*}\left(<Q_{a}^{*}\right)$ and the corresponding heat storage term is scaled linearly by the ratio $Q_{c b}^{*} / Q_{a}^{*}$. The sensible heat fluxes underneath the trees are therefore smaller than unshaded surfaces as a function of the shading effect of the canopy.

\section{Regime identification for tree cooling}

Before incorporating the tree model into an LES model, we analyse the tree model in order to to obtain fundamental insight into the cooling processes of trees in urban environments. The aim of this analysis is to provide a classification of tree cooling regimes that can be used to estimate 1) the cooling potential in specific conditions and 2) the attribution of cooling between transpiration and shading processes. This is achieved by comparing the magnitude and distribution of sensible heat fluxes due to the presence of a tree to the sensible heat flux under the same conditions with no tree present.

The fluxes of sensible heat from the unshaded ground surfaces, the shaded ground surfaces and the tree canopy to the surrounding air are important to consider in terms of: 1) the direct cooling potential of trees; and 2) the effects of buoyancy on pollution dispersion. As discussed in Section 1, the cooling potential of tree canopies is driven by two main processes:

1. Transpirational cooling; indicative of negative sensible heat fluxes between the tree canopy and the surrounding air. $Q_{H l}=Q_{l}^{*}-Q_{E l}<0$ and therefore $S_{T}<0$; see Equation 10 .

2. Shading; characterised by reduced sensible heat fluxes from the shaded surfaces and heat storage within the urban form. $Q_{H 0, s}<Q_{H 0}$; see section 2.4.

Both cooling processes are a function of the local environmental (radiation, wind, humidity etc.) and tree (leaf-area density, leaf size, stomatal resistance etc.) characteristics.

\subsection{Local transpirational cooling}

The latent heat flux, $Q_{E l}$, when decomposed into advective, $Q_{E l, o}$, and radiative, $Q_{E l, r}$, components in Equation 14 , is a function of the net radiative flux $Q_{l}^{*}$ itself, implying that the weighting of this relationship is significant. The relative magnitudes of each of these components of the latent heat flux term are therefore important and the ability to decompose this term can provide useful insight into the mechanism of transpirational cooling.

In order to investigate the attribution of transpiration between its advective and radiative components, we define the ratio (see Equation 14)

$$
\Gamma_{E}=\frac{Q_{E l, o}}{Q_{E l, r}}=\frac{2 \rho c_{p} D}{s r_{a} Q_{l}^{*}}
$$


which is zero for radiation-dominated transpiration and goes to infinity for advection-dominated transpiration. For the net effect of the transpiration to cool the air, it is required that $Q_{H l}=Q_{l}^{*}-Q_{E l}<0$. Rearranging Equation 10 and substituting yields

$$
Q_{H l}=\underbrace{-\omega_{l} \frac{2 \rho c_{p} D}{s r_{a}}}_{Q_{H l, o}}+\underbrace{\left(1-\omega_{l}\right) Q_{l}^{*}}_{Q_{H, r}}=\left(1-\omega_{l}\left(1+\Gamma_{E}\right)\right) Q_{l}^{*}<0 .
$$

The radiative component of the latent heat flux therefore acts against the available energy on the leaf surface to reduce the sensible heat flux by a factor proportional to $\omega_{l}$. This process alone cannot lead to net negative sensible heat fluxes but decreases the magnitude of the sensible heat flux as more of the available energy at the leaf surface is acting towards the process of transpiration. On the other hand, the advective component directly acts to reduce the magnitude of the sensible heat flux irrespective of $Q_{l}^{*}$ (as a function the vapour pressure deficit $D$ ). If the advective component is sufficiently large, one can therefore expect effective cooling and this process is called the 'oasis' effect. Equation 19 shows that the requirement for net cooling $Q_{H l}<0$ is

$$
\Gamma_{E}>\frac{1-\omega_{l}}{\omega_{l}},
$$

which indicates that the latent heat flux must be sufficiently weighted towards its advective component by a certain magnitude (a function of $\omega_{l}$ ) in order for a volume of leaves to have a net negative sensible heat flux.

The sensible heat flux from a volume of leaves can therefore be defined as a function of the dimensionless parameters $\omega_{l}$ and $\Gamma_{E}$. Forming the normalised leaf sensible heat flux $\hat{Q}_{H l}=Q_{H l} / Q_{l}^{*}$ and analysing this term as a function of $\omega_{l}$ and $\Gamma_{E}$ indicates that for greater values of $\omega_{l}$ (corresponding to lower stomatal resistances, higher aerodynamic resistances and higher air temperatures) and $\Gamma_{E}$ (corresponding to greater attribution of the advective as opposed to radiative component of the latent heat flux) the relative magnitude of the transpirational cooling is larger. The role of the aerodynamic resistance is complex as larger values act to reduce $\Gamma_{E}$ but increase $\omega_{l}$. These values apply for a volume of leaves and will therefore vary within a real tree canopy (a similar discussion point has been found when analysing the heterogeneity and time variability of the decoupling factor within tree canopies; Pereira, 2004). This relationship is discussed in more detail in Section 3.3 and displayed in Figure 3.

\subsection{Combined transpirational and shading cooling effects}

Further insight can be gained by extending this analysis to the tree model as a whole, i.e. by quantifying the difference between the combined energy balance system with and without the presence of a tree. Figure 4 diagrammatically shows the energy balances for the no-tree and with-tree cases for comparison.

The tree canopy is simplified via the assumption of uniform properties and the incoming environmental parameters are assumed constant throughout the canopy. Defining $H=z_{c t}-z_{c b}$ and following Equations 8 and 9, the total net radiation absorbed by the tree canopy $\Delta Q_{c}^{*}$ is given by

$$
\Delta Q_{c}^{*}=Q_{a}^{*}\left(1-e^{-\alpha d_{c b}}\right),
$$

where $d_{c b}=a H$ is the cumulative leaf area index over the entire tree canopy. With these assumptions, the average net radiation incident on the leaves is given by

$$
\left\langle Q_{l}^{*}\right\rangle=\frac{1}{H} \int_{z_{c b}}^{z_{c t}} Q_{l}^{*} \mathrm{~d} z=\frac{\Delta Q_{c}^{*}}{d_{c b}}
$$

and therefore the net latent and sensible heat fluxes from the tree canopy to the surrounding air are given by

$$
\begin{aligned}
Q_{E c} & =\omega_{l}\left(\frac{2 \rho c_{p} d_{c b} D}{s r_{a}}+\Delta Q_{c}^{*}\right), \\
Q_{H c} & =\left(1-\omega_{l}\right) \Delta Q_{c}^{*}-\omega_{l} \frac{2 \rho c_{p} d_{c b} D}{s r_{a}},
\end{aligned}
$$

respectively. Combined, Equations 21, 23 and 24 define the integral energy balance of the tree canopy per unit crown area, $\Delta Q_{c}^{*}=Q_{H c}+Q_{E c}$. 


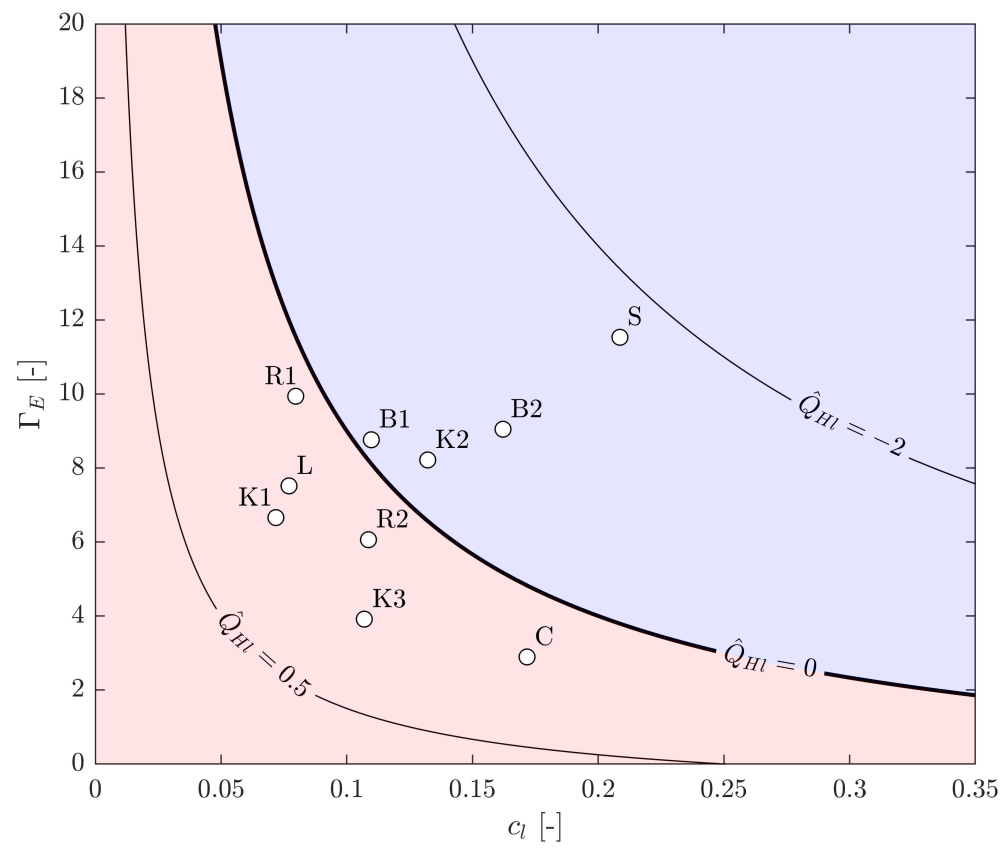

Figure 3. Normalised leaf sensible heat flux, $\hat{Q}_{H l}=Q_{H l} / Q_{l}^{*}$, plotted against the ratio between advective and radiative components of the leaf latent heat flux $\Gamma_{l}$ and the dimensionless parameter $\omega_{l}$. The red and blue areas signify positive and negative sensible heat fluxes respectively. The markers represent the values for the field studies outlined in Table 1.

No-tree case

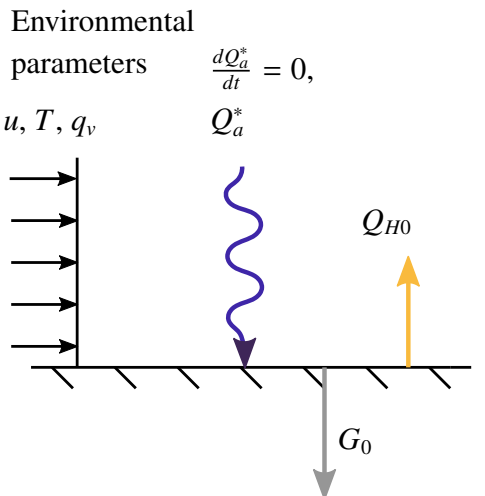

b)

$$
\frac{d Q_{a}^{*}}{d t}=0, Q_{a}^{*}\left(Q_{H t}=Q_{H c}+Q_{H 0, s}\right)
$$

Environmental parameters

$u, T, q_{v}$

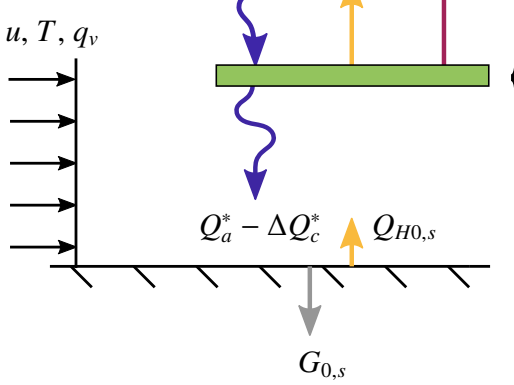

Tree parameters $d_{c b}, l, r_{s}, \alpha$

Figure 4. Diagram of the energy balance present in the a) no-tree and b) with-tree simplified cases. The tree canopy is collapsed diagramatically into a single layer. Uniform environmental and tree parameters are asssumed throughout. 
The surface model is simplified here by neglecting the transient term $\left(\mathrm{d} Q_{a}^{*} / \mathrm{d} t=0\right)$. The sensible heat flux from an unshaded ground surface (following Equations 16 and 17) is therefore

$$
Q_{H 0}=\left(1-A_{1}\right) Q_{a}^{*}-A_{3},
$$

which defines the total forcing to the atmosphere in the no-tree case, $Q_{H 0}$. Underneath the tree canopy, the sensible heat flux from the shaded surface is lower (as a function of the incoming net radiation for shaded surfaces; Section 2.4) following

$$
Q_{H 0, s}=\left(Q_{a}^{*}-\Delta Q_{c}^{*}\right)\left(1-A_{1}-\frac{A_{3}}{Q_{a}^{*}}\right) .
$$

A direct comparison can then be drawn by comparing the total sensible heat flux per crown area arising from the no-tree case, $Q_{H 0}$, against the with-tree case, $Q_{H t}$, which is defined by

$$
Q_{H t}=Q_{H c}+Q_{H 0, s} .
$$

The net thermal effect of the tree can therefore be normalised by dividing Equation 27 with Equation 25, which gives

$$
\frac{Q_{H t}}{Q_{H 0}}=\frac{1-\omega_{l}}{1-A_{1}-\frac{A_{3}}{Q_{a}^{*}}} \frac{\Delta Q_{t}^{*}}{Q_{a}^{*}}-\frac{\omega_{l}}{1-A_{1}-\frac{A_{3}}{Q_{a}^{*}}} \frac{2 \rho c_{p} d D}{s r_{a} Q_{a}^{*}}+\left(1-\frac{\Delta Q_{t}^{*}}{Q_{a}^{*}}\right)
$$

where the first, second and third terms on the right-hand side represent the dimensionless radiative, advective and shading contributions to the net sensible heat flux from the with-tree case. From this equation, it is clear that the cooling of a tree is governed by four dimensionless parameters:

$$
\omega_{l} \quad(29 \mathrm{a}) \quad \hat{Q}_{c}^{*}=\frac{\Delta Q_{c}^{*}}{Q_{a}^{*}} \quad(29 \mathrm{~b}) \quad \hat{Q}_{e}=\frac{2 \rho c_{p} d_{c b} D}{s r_{a} Q_{a}^{*}} \quad(29 \mathrm{c}) \quad \hat{Q}_{H 0}=1-A_{1}-\frac{A_{3}}{Q_{a}^{*}}
$$

where $\omega_{l}$ is the parameter introduced in Equation 14, $\hat{Q}_{c}^{*}$ is the proportion of the net radiation 'absorbed' by the tree canopy, $\hat{Q}_{e}$ is the dimensionless transpirational cooling term and $\hat{Q}_{H 0}$ is the dimensionless ground sensible heat flux. In terms of these four characteristic dimensionless parameters, Equation 28 can be written as

$$
\frac{Q_{H t}}{Q_{H 0}}=\underbrace{\beta_{\frac{Q_{H, r}}{Q_{H 0}}}^{\beta_{1} \hat{Q}_{c}^{*}}-\underbrace{\beta_{2} \hat{Q}_{e}}_{\frac{Q_{H c, 0}}{Q_{H 0}}}}_{\frac{Q_{H c}}{Q_{H 0}}}+\underbrace{\left(1-\hat{Q}_{c}^{*}\right)}_{\frac{Q_{H 0, s}}{Q_{H 0}}}
$$

where $\beta_{1}=\left(1-\omega_{l}\right) / \hat{Q}_{H 0}$ and $\beta_{2}=\omega_{l} / \hat{Q}_{H 0}$. The equation above shows clearly that the cooling of trees is a linear function of $\hat{Q}_{c}^{*}$ and $\hat{Q}_{e}$.

In order to define regimes for the expected thermal effect of trees (see Figure 5), we introduce two new indicators. The net tree cooling $(N T C)$ coefficient

$$
N T C=\frac{Q_{H 0}-Q_{H t}}{Q_{H 0}}=\left(1-\beta_{1}\right) \hat{Q}_{c}^{*}+\beta_{2} \hat{Q}_{e}
$$

quantifies the cooling potential of the tree (via both transpiration and shading). A value of $N T C>1$ indicates that the total sensible heat flux in the with-tree case is negative and that there is therefore a net cooling of the surrounding air. A value of $0<N T C<1$ indicates that the total sensible heat flux in the with-tree case is positive but smaller than that in the no-tree case therefore resulting in a net reduction of sensible heat. A value of $N T C<0$ suggests that the net thermal effect of the tree is to warm the surrounding air by a larger magnitude than in the no-tree case.

The second parameter to quantify the cooling regime is the tree cooling ratio $(T C R)$, defined as

$$
T C R=\frac{Q_{H c}}{Q_{H 0, s}-Q_{H 0}}=\frac{\beta_{1} \hat{Q}_{c}^{*}-\beta_{2} \hat{Q}_{e}}{-\hat{Q}_{c}^{*}} .
$$




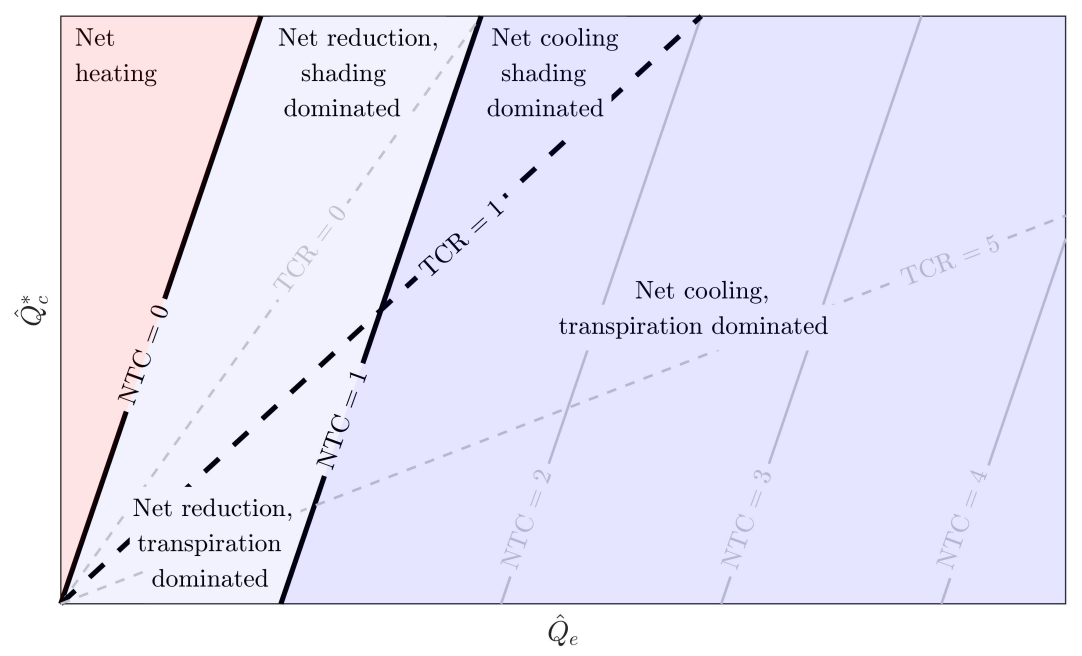

Figure 5. Regime diagram for tree cooling based upon the dimensionless parameters $\hat{Q}_{c}^{*}$ and $\hat{Q}_{e}$. The thick black lines signify regime boundaries and the grey lines illustrate additional lines of interest. Solid lines signify the net tree cooling (NTC) and dashed lines represent the tree cooling ratio $(T C R)$.

The $T C R$ quantifies the relative contributions of shading and transpiration. A value of $T C R>1$ indicates that the cooling process is dominated by transpirational cooling (the 'oasis' effect) and $T C R<1$ indicates that the shading effect takes prominence ( $T C R<0$ indicates that the net sensible heat flux from the tree canopy is positive). Figure 5 plots the regimes that can be identified using the dimensionless parameters $\hat{Q}_{c}^{*}$ and $\hat{Q}_{e}$. The axes provide an indication of the proportion of net radiation absorbed by the tree canopy and the magnitude of the advective component of the latent heat flux. It is important to note that the position of the regime division lines depends on $\beta_{1}$ and $\beta_{2}$ and will therefore be different for each case of interest (varying with $\hat{Q}_{H 0}$ and $\omega_{l}$ ). The regime diagram provides a useful tool to visualise the different thermal effects of any tree under any set of conditions. The regimes indicate the difference between net reductions in sensible heat and net cooling and the relative attribution of the transpiration and shading cooling mechanisms.

\subsection{Application to existing to field studies}

The above analysis relies on significant simplifications and assumptions but presents a very useful tool in developing our understanding of the thermal effects of trees, particularly with regard to the natural variability and case specificity. Manickathan et al. (2018) present a parametric study of trees in a cross-flow wind that is an effective case for analysing the sensitivity of transpirational cooling to a range of environmental and tree parameters. The trends identified by Manickathan et al. (2018) can be reproduced using the simple analytical model developed above, even extending it with shading effects and a decomposition of the radiative and advective components of the latent heat flux.

Table 1 displays values of tree and environmental parameters extracted and inferred from various field studies on urban tree canopies. The set of studies encompass a range of tree species, locations and climatic conditions. The data is limited by the availability of the required information and the assumption of uniform properties (as depicted in Figure 4). However, using this data within the dimensionless framework outlined in Sections 3.1 and 3.2 provides a way to contextualise the regimes and parameters and to highlight the capabilities of this methodology.

The normalised canopy-averaged sensible heat fluxes for this set of tree canopies, as estimated by the tree model, are plotted in Figure 3 (the average net radiation incident on the leaves for the canopy is used; see Equation 22). The spread of the data points illustrate the differences in transpirational cooling processes that arise as a result of differing tree and environmental parameters. This simple approach captures some of the meaningful trends from these research articles. For example, Rahman et al. (2017) indicate that the tree in the open green space (R1) provides 
slightly larger transpirational cooling during the day which is manifested in the lower value of $\hat{Q}_{H l}$ for R1 as opposed to R2 (the main differences between these trees are in the humidity and the local wind speed). Similarly, the model predicts that the Quercus Robur (K2) provides the most significant transpirational cooling of the chosen trees in the study of Konarska et al. (2016). This occurs as a result of the relatively lower stomatal resistance, higher leaf-area density and lower humidity in comparison to R1 and R3. The most significant transpirational cooling is found in the study of Shashua-Bar et al. (2009), where a combination of low humidity and low stomatal resistance provides an effective 'oasis' effect. These results provide approximations and are limited by the availability of the required data. In particular, values for stomatal resistance were only available from Konarska et al. (2016) of all of these studies. This value is highly significant and dependant on numerous other factors and is therefore imperative to produce accurate estimations (see Section 2.3.3). Direct evaluations of the model predictions are also challenging as the sensible heat flux is not generally calculated in such studies.

The field studies can also be analysed in relation to the regime diagram. Of particular interest is the study of Shashua-Bar et al. (2009), which was used by Gromke et al. (2015) to define a parameterisation for volumetric tree cooling as a function of the leaf-area density $\left(250 \mathrm{~W} \mathrm{~m}^{-3}\right.$ per unit leaf-area density $a$ ). Figure 6 a plots the field study of Shashua-Bar et al. (2009) on a tree regime diagram. The case study is shown to be well within the net cooling, transpiration dominated regime with an NTC of 3.6 and TCR of 4.15. A pathway is plotted on Figure 6a that indicates the change in $\hat{Q}_{c}^{*}$ and $\hat{Q}_{e}$ due to a change in leaf-area density. This line indicates that for $a>0.1$ the studied tree lies consistently within this regime. The value of $\hat{Q}_{c}^{*}$ tends towards 1 with increasing $a$ and is relatively constant for $a>1.25 \mathrm{~m}^{2} \mathrm{~m}^{-3}$ (consistent with a leaf area index $d_{c b}>3 / \alpha$ ). Moreover, $\hat{Q}_{e}$ increases linearly with increasing $a$.

Figure $6 \mathrm{~b}$ breaks down the net sensible heat flux for the with-tree for varying leaf-area density. The quasi-linear trend is shown to satisfy Gromke et al. (2015)'s parameterisation $\left(Q_{H t} \approx-3000 \mathrm{~W} \mathrm{~m}^{-2}\right.$ for $a=2 \mathrm{~m}^{2} \mathrm{~m}^{-3}$ and $H=6$ $\mathrm{m}$ indicating a volumetric cooling of $500 \mathrm{~W} \mathrm{~m}^{-3}$ and therefore $250 \mathrm{~W} \mathrm{~m}^{-3}$ per unit leaf-area density). The linearity in this case arises due to the dominance of the advective component of the canopy sensible heat flux $Q_{H c, o}$. The radiative component $Q_{H c, r}$ and the shading effect $Q_{H 0, s}-Q_{H 0}$ do not increase linearly (tending towards a maximum value; reached at $d_{c b} \approx 3 / \alpha$ ) however due to the prevalence of advective transpirational cooling the relationship remain quasi-linear (following $\hat{Q}_{e}$ ).

The linear relationship between the canopy sensible heat flux $Q_{H c}$ and leaf-area density $a$ proposed by Gromke et al. (2015) is therefore highly case-specific. The relative humidity (35\%) and inferred stomatal resistance (150 s $\mathrm{m}^{-1}$ ) in the Shashua-Bar et al. (2009) case study are low, which drives the dominance of the advective component and the strong 'oasis' effect ( $\hat{Q}_{H l}$ is much smaller for this case study than the others in Figure 3 ). This finding is illustrated by the pathway of changing relative humidity in Figure 6a. For the same leaf-area density, an increase in relative humidity shifts the position of the case study in the regime diagram to lower $N T C \mathrm{~s}$ as a function of $\hat{Q}_{e}$ (the humidity does not affect $\hat{Q}_{c}^{*}$ ). This effect is a result of the change in the humidity of the incoming air, which directly reduces the transpirational cooling and therefore the 'oasis' effect (a linear relationship between cooling and the vapour pressure deficit has been found in numerous studies; Rahman et al., 2017; Manickathan et al., 2018). For relative humidities of $\approx 70 \%$ and greater the case study is shown to enter the shading-dominated regime. For higher humidities, the same change in leaf-area density will not lead to a linear increase in cooling over these regimes. Moreover, even at high leaf-area densities where $\hat{Q}_{c}^{*}$ is relatively constant, the magnitude of the linear increase in will not necessarily be $250 \mathrm{~W} \mathrm{~m}^{-2}$ per unit leaf-area density as this value depends on the magnitude of the other variables that define $\hat{Q}_{e}$ in Equation 29c. It is therefore suggested that this parameterisation is unsuitable for application to other LES studies unless the required case-specific environmental and tree parameters are acknowledged.

\section{Incorporation into the urban large-eddy simulation model uDALES}

The above analysis provides a useful tool for improving our understanding of the attributions and case specificity of tree's thermal effects. There is also a need to 1) resolve these fluxes at higher resolutions in order to understand the distribution and locality of sensible heat fluxes within tree canopies and 2) to resolve the unsteady, turbulent flow field within the urban canopy layer to obtain accurate estimations of the environmental variables (humidity, temperature and wind speed) at high resolutions. By integrating the model into LES, the environmental parameters can be accurately modelled dependant on e.g. the atmospheric stability and the local urban morphology.

Incorporating the tree model outlined in Section 2 into LES implies that the tree effects are time-resolved with respect to the turbulent and unsteady air that flows through the tree canopy. LES models resolve the flow at the 
a)
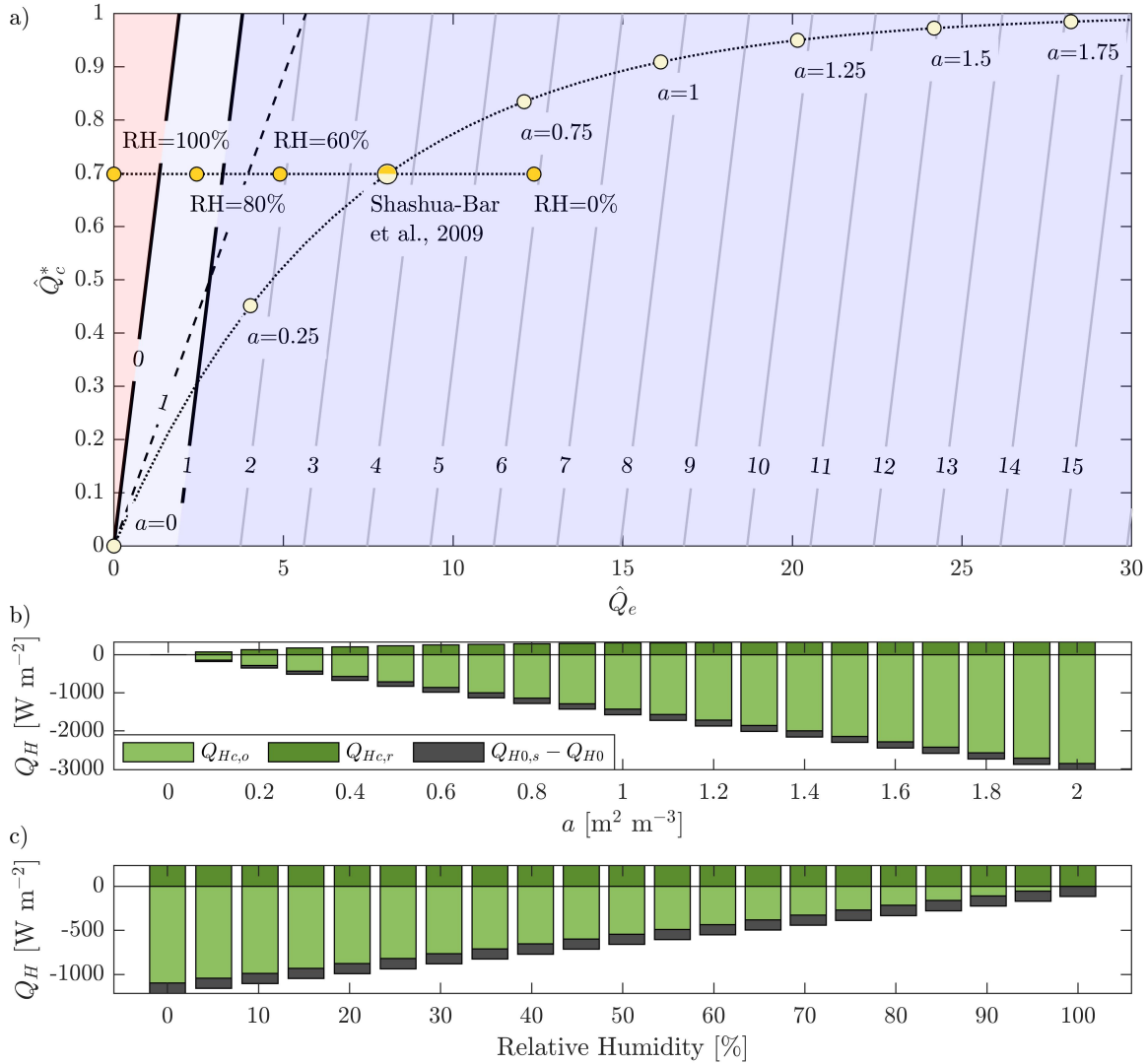

Figure 6. a) Tree cooling regime diagram with net tree cooling (NTC) lines plotted to indicate the magnitude of tree cooling. Pathways of varying leaf-area density $a$ and relative humidity (RH) are plotted to show the sensitivity of the Shashua-Bar et al. (2009) case study to these variables. Stacked bar charts showing the breakdown of the total with-tree sensible heat flux $Q_{H t}$ against b) leaf-area density and c) relative humidity. 
Table 1. Bulk environmental and tree parameters extracted and inferred from, details of and calculated dimensionless coefficients for a set of real field studies of urban trees. The environmental and tree parameters have been collated from data in the respective research articles where possible. Grey, italic numbers indicate that the values were not directly attainable from the relevan publication. In this case, either default values are used (e.g. $u=1 \mathrm{~m} \mathrm{~s}^{-1}$ ) or values are inferred from the text (e.g. using latitude, date and cloud cover to get net radiation (Soulhac et al., 2011)) or finding average leaf sizes for specific tree species). In all cases, data is taken from the middle of the day (1200-1500).

\begin{tabular}{|c|c|c|c|c|c|c|c|c|c|c|c|c|c|c|c|c|}
\hline \multirow{3}{*}{ Study } & \multirow{3}{*}{ Location } & \multirow{3}{*}{ Species } & \multirow{3}{*}{ Details } & \multirow{2}{*}{\multicolumn{9}{|c|}{ Parameters }} & \multirow{2}{*}{\multicolumn{3}{|c|}{$\begin{array}{l}\text { Dimensionless } \\
\text { coefficients }\end{array}$}} & \multirow{3}{*}{ Regime } \\
\hline & & & & Environmental & & & & & & & & \multirow[b]{2}{*}{$\alpha$} & & & & \\
\hline & & & & $\begin{array}{c}u \\
\mathrm{~m} \mathrm{~s}^{-1}\end{array}$ & $\begin{array}{l}\mathrm{RH} \\
\%\end{array}$ & $\begin{array}{l}\theta \\
\mathrm{K}\end{array}$ & $\begin{array}{c}Q_{a}^{*} \\
\mathrm{~W} \mathrm{~m}^{-2}\end{array}$ & $\begin{array}{c}a \\
\mathrm{~m}^{2} \mathrm{~m}^{-3}\end{array}$ & $\begin{array}{l}H \\
\mathrm{~m}\end{array}$ & $\begin{array}{l}l \\
\mathrm{~m}\end{array}$ & $\begin{array}{c}r_{s} \\
\mathrm{~s} \mathrm{~m}^{-1}\end{array}$ & & $\hat{Q}_{H l}$ & NTC & $T C R$ & \\
\hline $\begin{array}{l}\text { R1 (Rahman et al., } \\
\text { 2017) }\end{array}$ & $\begin{array}{l}\text { Munich, } \\
\text { Germany }\end{array}$ & $\begin{array}{l}\text { Tilia } \\
\text { Cordata }\end{array}$ & $\begin{array}{l}\text { Open green } \\
\text { square }\end{array}$ & 1.26 & 39.3 & 293.7 & 327.6 & 0.24 & 9.0 & 0.055 & 300 & 0.4 & 0.13 & 0.40 & -0.31 & $\begin{array}{l}\text { Net reduction, shading } \\
\text { dominated }\end{array}$ \\
\hline $\begin{array}{l}\text { R2 (Rahman et al., } \\
\text { 2017) }\end{array}$ & $\begin{array}{l}\text { Munich, } \\
\text { Germany }\end{array}$ & $\begin{array}{l}\text { Tilia } \\
\text { Cordata }\end{array}$ & $\begin{array}{l}\text { Circular } \\
\text { paved } \\
\text { square }\end{array}$ & 0.59 & 49.0 & 293.7 & 327.6 & 0.25 & 10.0 & 0.055 & 300 & 0.4 & 0.23 & 0.28 & -0.56 & $\begin{array}{l}\text { Net reduction, shading } \\
\text { dominated }\end{array}$ \\
\hline L (Lindén et al., 2016) & $\begin{array}{l}\text { Mainz, } \\
\text { Germany }\end{array}$ & $\begin{array}{l}\text { Tilia platy- } \\
\text { phyllos }\end{array}$ & Park & 1.80 & 60.9 & 293.4 & 430.7 & 0.4 & 12.0 & 0.075 & 300 & 0.4 & 0.34 & 0.10 & -0.89 & $\begin{array}{l}\text { Net reduction, shading } \\
\text { dominated }\end{array}$ \\
\hline C (Chen et al., 2019) & $\begin{array}{l}\text { Guangzhou, } \\
\text { China }\end{array}$ & $\begin{array}{l}\text { Schima } \\
\text { superba }\end{array}$ & $\begin{array}{l}\text { Garden } \\
\text { with tall } \\
\text { buildings }\end{array}$ & 1.00 & 74.2 & 303.3 & 404.6 & 0.48 & 9.0 & 0.100 & 300 & 0.4 & 0.33 & 0.10 & -0.88 & $\begin{array}{l}\text { Net reduction, shading } \\
\text { dominated }\end{array}$ \\
\hline B1 (Barradas, 2000) & $\begin{array}{l}\text { Mexico } \\
\text { City, } \\
\text { Mexico }\end{array}$ & $\begin{array}{l}\text { Fraxinus } \\
\text { uhdei }\end{array}$ & Dry season & 2.20 & 12.5 & 295.7 & 505.0 & 0.73 & 6.0 & 0.225 & 350 & 0.4 & -0.07 & 0.98 & 0.19 & $\begin{array}{l}\text { Net reduction, shading } \\
\text { dominated }\end{array}$ \\
\hline B2 (Barradas, 2000) & $\begin{array}{l}\text { Mexico } \\
\text { City, } \\
\text { Mexico }\end{array}$ & $\begin{array}{l}\text { Fraxinus } \\
\text { uhdei }\end{array}$ & Wet season & 2.70 & 25.5 & 300.4 & 495.0 & 0.77 & 6.0 & 0.225 & 250 & 0.4 & -0.63 & 2.25 & 1.67 & $\begin{array}{l}\text { Net cooling, transpira- } \\
\text { tion dominated }\end{array}$ \\
\hline $\begin{array}{l}\text { K1 (Konarska et al., } \\
\text { 2016) }\end{array}$ & $\begin{array}{l}\text { Gothenburg, } \\
\text { Sweden }\end{array}$ & $\begin{array}{l}\text { Tilia } \\
\text { europaea }\end{array}$ & Park & 1.00 & 44.0 & 293.1 & 404.3 & 0.41 & 10.4 & 0.105 & 508 & 0.4 & 0.45 & -0.12 & -1.14 & Net heating \\
\hline $\begin{array}{l}\text { K2 (Konarska et al., } \\
\text { 2016) }\end{array}$ & $\begin{array}{l}\text { Gothenburg, } \\
\text { Sweden }\end{array}$ & $\begin{array}{l}\text { Quercus } \\
\text { robur }\end{array}$ & $\begin{array}{l}\text { Heavy } \\
\text { traffic } \\
\text { street }\end{array}$ & 1.00 & 40.9 & 295.9 & 404.3 & 1.10 & 4.9 & 0.110 & 289 & 0.4 & -0.22 & 1.37 & 0.55 & $\begin{array}{l}\text { Net cooling, shading } \\
\text { dominated }\end{array}$ \\
\hline $\begin{array}{l}\text { K3 (Konarska et al., } \\
\text { 2016) }\end{array}$ & $\begin{array}{l}\text { Gothenburg, } \\
\text { Sweden }\end{array}$ & $\begin{array}{l}\text { Prunus } \\
\text { serrulata }\end{array}$ & $\begin{array}{l}\text { Lawn close } \\
\text { to building }\end{array}$ & 1.00 & 64.0 & 292.6 & 404.3 & 0.92 & 3.9 & 0.102 & 299 & 0.4 & 0.47 & -0.16 & -1.20 & Net heating \\
\hline $\begin{array}{l}\text { S (Shashua-Bar et al., } \\
2009 \text { ) }\end{array}$ & $\begin{array}{l}\text { Negev, } \\
\text { Israel }\end{array}$ & $\begin{array}{l}\begin{array}{l}\text { Prosopis } \\
\text { juliflora }\end{array} \\
\text { a }\end{array}$ & Courtyard & 2.00 & 35.0 & 305.2 & 424.9 & 0.50 & 6.0 & 0.070 & 150 & 0.4 & -1.62 & 3.60 & 4.15 & $\begin{array}{l}\text { Net cooling, transpira- } \\
\text { tion dominated }\end{array}$ \\
\hline
\end{tabular}


energetically dominant scales of turbulent motion by filtering the Navier-Stokes equations. They are therefore computationally faster than direct numerical simulation (DNS) models and capable of resolving the unsteadiness of turbulent flow fields unlike RANS models.

The LES model used in this study is uDALES (Tomas et al., 2015; Grylls et al., 2019; Suter et al., 2020), which solves the filtered Navier-Stokes and scalar conservation equations

$$
\begin{aligned}
& \frac{\partial \widetilde{u_{i}}}{\partial x_{i}}=0 \\
& \frac{\partial \widetilde{u_{i}}}{\partial t}=-\frac{\partial}{\partial x_{j}}\left(\widetilde{u_{j}} \widetilde{u_{i}}\right)-\frac{1}{\rho_{0}} \frac{\partial \Pi}{\partial x_{i}}+\frac{g}{\theta_{0}} \widetilde{\theta_{\nu}} \delta_{i 3}-\frac{\partial \tau_{i j}}{\partial x_{j}}+\mathcal{F}_{i}+S_{u_{i}} \\
& \frac{\partial \widetilde{\psi}}{\partial t}=-\frac{\partial}{\partial x_{j}}\left(\widetilde{u_{j}} \widetilde{\psi}\right)-\frac{\partial \mathcal{R}_{\psi, j}}{\partial x_{j}}+S_{\psi}
\end{aligned}
$$

where ... denotes low-pass filtering at the scale of the grid, $\rho_{0}$ is a reference value of the density of air, $\Pi$ is the modified pressure, $g$ is the gravitational acceleration, $\theta_{v}$ is the virtual potential temperature, $\theta_{0}$ is a reference value of virtual potential temperature, $\delta_{i 3}$ is the Kroenecker delta, $\tau$ is the deviatoric component of the subgrid-scale (SGS) momentum flux (the normal components are resolved within $\Pi$ ), $\mathcal{F}_{i}$ represents other large-scale forces on the flow and $S_{u_{i}}$ is the drag term present due to the presence of a tree canopy (see Section 2.1). In Equation 35, $\psi$ is a scalar field that represents the potential temperature $(\theta)$, specific humidity $(q)$ or pollutant fields $(\varphi)$. $\mathcal{R}_{\psi, j}$ is the SGS scalar flux vector and $S_{\psi}$ represents volumetric source/ sink terms arising due to the presence of a tree canopy or surface heat flux (see Sections 2.2, 2.3 and 2.4). Note that a volumetric source/sink term for temperature, $S_{T}$, is defined in Section 2 , thus requiring an adjustment from air potential temperature, $\theta$, to air temperature, $T$, at non-zero altitudes (Heus et al., 2010). The virtual potential temperature, $\theta_{v}$, is defined following Emanuel (1994)

$$
\theta_{v}=\theta\left(1-\left(1-\frac{R_{v}}{R_{d}}\right)\left(q_{v}+q_{l}\right)-\frac{R_{v}}{R_{d}} q_{l}\right)
$$

where $\theta$ is the potential temperature, $q_{v}$ is the water vapour specific humidity, $q_{l}$ is the liquid water specific humidity, $R_{v}$ and $R_{d}$ are the gas constants for water vapour and dry air respectively. For the applications of uDALES conducted in this study, liquid water is not present such that $q_{l}=0$.

The gradient diffusion hypothesis is used to close the subgrid scale terms. The eddy viscosity is calculated following Vreman (2004). Buildings are modelled within the domain following the immersed boundary method (Tomas et al., 2015). Log-law wall functions are used to resolve the dynamics close to the walls (Uno et al., 1988; Suter, 2018). The grid is spatially discretised on an Arakawa C-grid utilising a second-order central-differencing scheme for all field variables except for the pollution concentration, which employs a $\kappa$ scheme to ensure positivity. A third-order Runge-Kutta time integration scheme is applied.

\section{Large-eddy simulations of tree canopies}

The results for the fully integrated tree LES model will be described in this section with a focus on validating aspects of the model against existing datasets. The challenges associated with the scaling of vegetation for experimental studies mean that there is a paucity of validation cases to apply the tree model to (particularly ones that include thermal effects; Gromke et al., 2015). In the following section we therefore validate the formulation of the tree model against existing numerical studies. In doing so, we also present results that can be used to evaluate the performance of future vegetation models. Figure 7 illustrates the three simulation set-ups that are explored in this section: a full-canopy, half-canopy and a single row of trees.

\subsection{Full-canopy}

The full canopy set-up has been studied extensively both to better understand the mesoscale effects of forest canopies on the ABL and to validate the drag applied across various vegetation models (Shaw and Schumann, 1992; Xie and Li, 2005; Gu et al., 2010). Here, the full-canopy set-up is used to validate the implementation of the drag model (Section 2.1) in UDALES. 


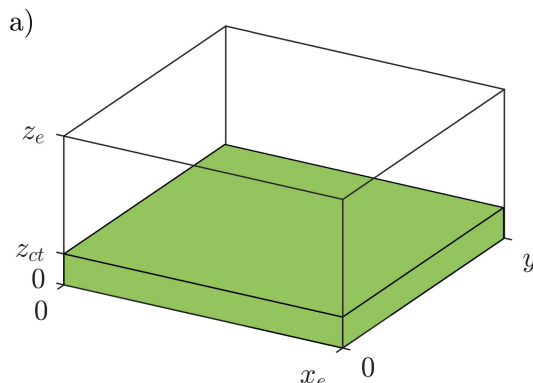

c)

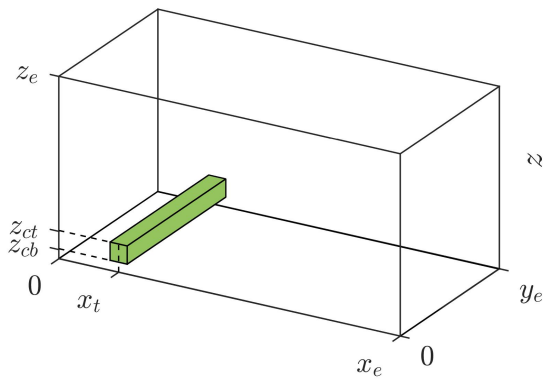

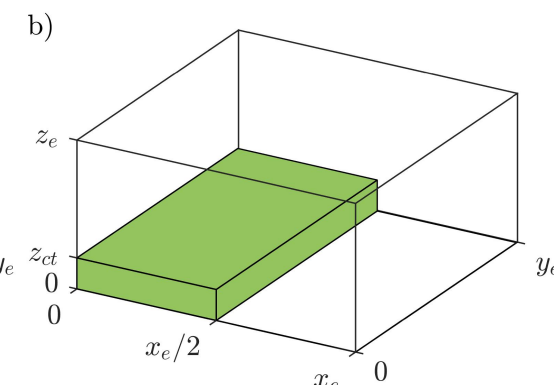

e) d)

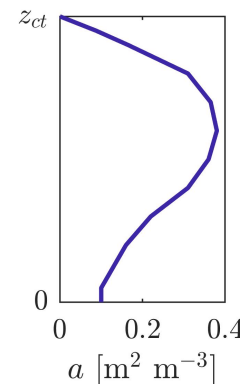

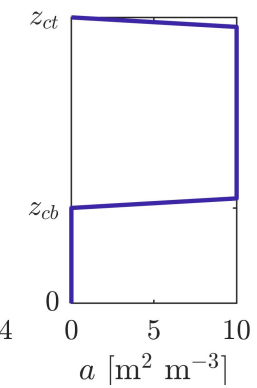

Figure 7. a) Full-canopy, b) half-canopy and c) a single row of trees (following Manickathan et al., 2018) domain and canopy set-ups for the simulations. d), e) leaf-area density profiles applied within this set of simulations.

\subsubsection{Simulation set-up}

The simulation set-up of Shaw and Schumann (1992) is followed in defining a domain size of $192 \times 96 \times 60 \mathrm{~m}$ with a horizontally homogeneous tree canopy of height $H=20 \mathrm{~m}$ (see Figure 7a). The cell size is $1 \mathrm{~m}$ in all directions. A constant volume flow rate is set in the streamwise direction enforcing a bulk wind speed of $2 \mathrm{~m} \mathrm{~s}^{-1}$, periodic boundary conditions are defined in the horizontal directions and a free-slip condition is set at the top of the domain. Neutral conditions were used for the case of the drag validation. Wall functions are applied at the bottom of the domain with a roughness length of $0.02 \mathrm{~m}$. The tree canopy properties are a non-uniform vertical profile of leaf-area density with a leaf area index $d_{c b}$ of 2 (as shown in Figure 7d) and a drag coefficient of 0.15. The full-canopy simulation was run up for a period of $26000 \mathrm{~s}$ such that it is fully developed and has reached a statistical steady state. The results were taken over a further $2000 \mathrm{~s}$ averaging period with a sampling time of $2 \mathrm{~s}$.

\subsubsection{Results}

Figure 8 compares the mean velocity and Reynolds stress profiles obtained in uDALES and compared against the results of Shaw and Schumann (1992), Xie and Li (2005) and Gu et al. (2010). Good agreement is provided both within and above the tree canopy. These profiles show qualitative agreement with those found in field studies of forest canopies. The mean wind speed is near-logarithmic above the canopy, there is a quasi-exponential decay of velocity in the upper half of the canopy, the parameter $u(0.25 H) / u(1.4 H)=0.27$ agrees with observation (equivalent value of 0.28 in Cionco, 1979) and there is a reversal in the velocity gradient in the lower half of the canopy (Shaw and Schumann, 1992). These results indicate that the implementation of the drag model is consistent with these previous studies.

\subsection{Single row of trees}

The canopy energy balance model is validated using the single-row-of-trees set-up (Figure 7c). The set-up mimics that of Manickathan et al. (2018). In that study, the tree shading effect is neglected, but Manickathan et al. (2018) provide a simulation set-up that enables a validation of the tree canopy energy balance model (with adjustments made considering the differences between the two models and tree modelling approaches). 

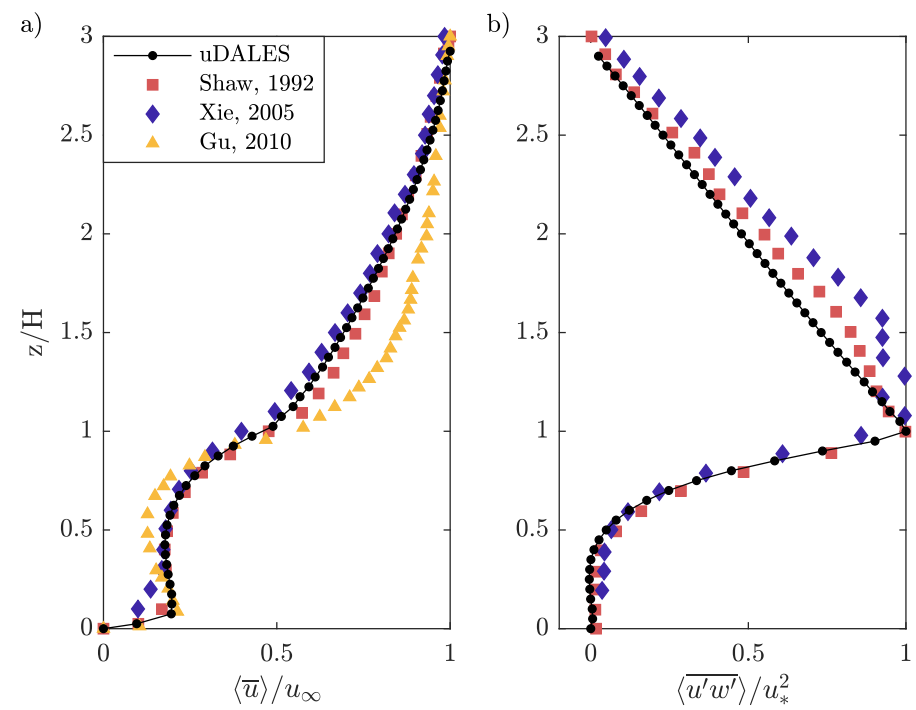

Figure 8. Time and spanwise averaged profiles of (a) mean streamwise velocity and (b) turbulent momentum flux for the full-canopy simulation. Comparison against three other numerical studies.

\subsubsection{Simulation set-up}

In order to model a fully-developed, neutral upwind boundary layer (without the effects of the tree wake), a precursor (driver) simulation was used to calculate the velocity field at the inlet. The domain size of the driver simulation is $20 \times 10 \times 10 \mathrm{~m}$ with a resolution of $0.05 \mathrm{~m}$ in all directions. A constant volume flow rate is specified with a bulk wind speed of $1.35 \mathrm{~m} \mathrm{~s}^{-1}$. Periodic boundary conditions are used in the horizontal directions, a free-slip condition is applied at the domain top and the roughness length of the ground surface is $0.018 \mathrm{~m}$. The driver simulation is run-up for $1000 \mathrm{~s}$ and a further $1500 \mathrm{~s}$ are used to drive the inlet of the single-row-of-trees simulation.

The domain size and top and bottom boundary conditions for momentum of the single-row-of-trees simulation are identical to those of the driver simulation. Uniform profiles of potential temperature $(\theta=303.15 \mathrm{~K})$ and specific humidity $\left(q_{v}=0.016 \mathrm{~kg} \mathrm{~kg}^{-1}\right)$ are assigned at the inlet and a convective outflow condition is imposed at the outlet plane. Periodic spanwise boundary conditions and zero-flux top and bottom boundary conditions are applied for potential temperature and specific humidity. The urban surface energy balance discussed in Section 2.4 is switched off (zero surface heat flux) in order to enable a direct comparison with Manickathan et al. (2018). The tree is $1 \mathrm{~m}$ wide in the streamwise direction, $1 \mathrm{~m}$ tall, positioned $3 \mathrm{~m}$ from the inlet boundary (see Figure $7 \mathrm{c}$ ) and $0.5 \mathrm{~m}$ above ground level. The drag coefficient $C_{d}=0.2$, the extinction coefficient $\alpha=0.78$, the leaf-area density $a=10$ and is uniform over the tree height (see Figure 7e), the net radiation above the canopy $Q_{a}^{*}=797 \mathrm{~W} \mathrm{~m}^{-2}$, the leaf size $l=0.1 \mathrm{~m}$ and the stomatal resistance $r_{s}=150 \mathrm{~s} \mathrm{~m}^{-1}$.

\subsubsection{Results}

Figure 9 shows the instantaneous, mean and root-mean-square fields from the single-row-of-trees simulation. The wake of the tree can be seen to extend downstream from the tree canopy. The mean profiles are qualitatively similar to the mean values obtained from the RANS model in Manickathan et al. (2018). Figure 9a, d and g display instantaneous fields of momentum, potential temperature and specific humidity respectively. The ability to time resolve the turbulent dynamics of the air in this way is a key advantage of LES in comparison to RANS (where the turbulence is parameterised and only mean properties are produced).

Figure 10a compares the net radiative, sensible heat and latent heat fluxes at the leaf surfaces at the centre of the modelled tree $(x=3.5 \mathrm{~m})$ from uDALES and compares them to the results obtained in the RANS simulation of Manickathan et al. (2018). The fluxes are averaged in time and in the spanwise direction in uDALES. A good agreement is observed between the two models. The radiative budget applied in the tree model captures the same exponential decay of radiative energy down through the tree canopy. The modelled sensible and latent heat fluxes are 
a)

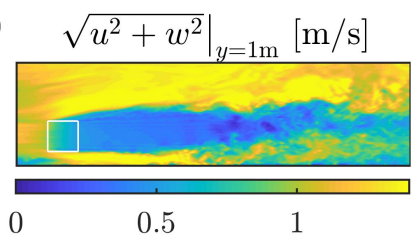

d)

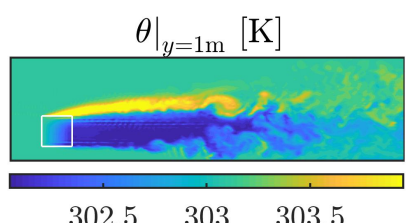

g)

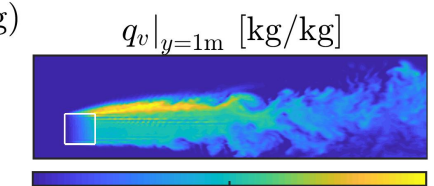

0.016

0.0165 b)

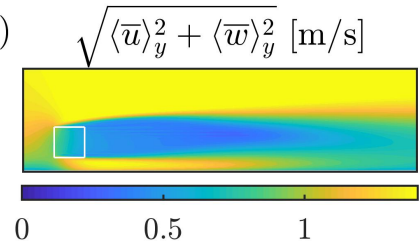

e)

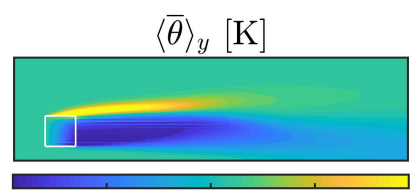

$\begin{array}{lll}302.5 & 303 & 303.5\end{array}$

h)

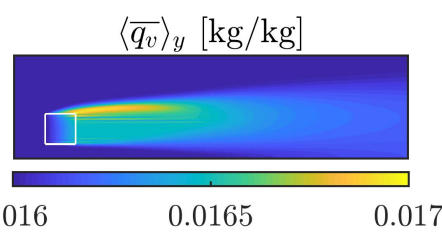

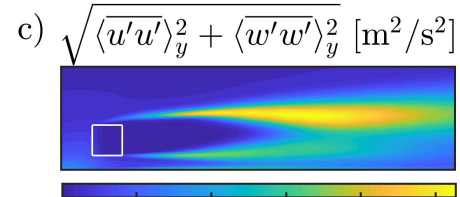

$\begin{array}{llllll}0.02 & 0.04 & 0.06 & 0.08 & 0.1\end{array}$

f)

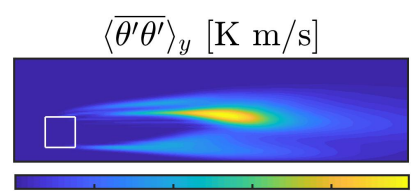

$\begin{array}{llll}0.05 & 0.1 & 0.15 & 0.2\end{array}$

i)

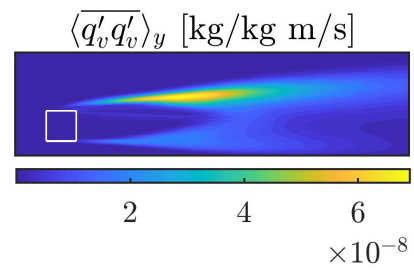

Figure 9. Instantaneous, mean and root-mean-square fields of wind speed (a, b and c), potential temperature (d, e and f) and water vapour specific humidity $(\mathrm{g}, \mathrm{h}$ and $\mathrm{i})$ for the single-row-of-trees simulation. The white box indicates the position of the tree canopy.

also very similar. This finding illustrates that the application of the Penman transformation produces equivalent results to a model in which the leaf temperature is resolved through an iterative process The small differences that are evident between the two models may be partly associated with the different modelling approaches but also occur due to the differences between the inflow conditions between the RANS simulation and the LES. The oncoming wind speed is not perfectly matched which results in small deviations in the drag characteristics of the tree and to the aerodynamic resistances. However, these differences are shown to be minimal in Figure 10a.

Similar to the case discussed in Section 5.3, the net radiation on the leaf surfaces is larger than the latent heat flux at the top of the tree canopy and therefore the sensible heat flux is positive. As the net radiation decays through the tree canopy, this effect is reversed and the sensible heat flux is negative.

The latent heat flux is decomposed into its radiative and advective components in Figure 10b. The advective component is relatively uniform across the height of the tree due to the uniform upwind profiles of potential temperature and specific humidity. The radiative component results in an increase in the total latent heat flux towards the top of the canopy. The breakdown of these two terms further indicates how the advective cooling effect acts independently to the radiative balance. For this case, a change in e.g. the relative humidity of the oncoming air acts to directly change the magnitude of $Q_{E l, o}$. This point further emphasises that, under conditions where the advective component of the latent heat flux is much larger than the net radiative energy incident on the leaf surface, this process will dominate throughout the tree canopy. As this term decreases and is of similar magnitude to the radiative flux, the tree both warms and cools the air in different positions.

The thermal effect of the tree in this case can also be estimated by applying the analysis in Section 3 . In fact the single row of trees set-up replicates the simplifications and assumptions used to formulate that approach (see Figure 4). Assuming a bulk velocity of $1.1 \mathrm{~m} \mathrm{~s}^{-1}$, one gets a normalised average leaf sensible heat flux $\hat{Q}_{H l}=-0.60$ corresponding to an average leaf sensible heat flux of $-47.5 \mathrm{~W} \mathrm{~m}^{-2}$. This estimation is very close to the average leaf sensible heat flux at the leading edge of the tree as calculated in the LES simulation $\left(-46.8 \mathrm{~W} \mathrm{~m}^{-2}\right)$. As the environmental variables change within the tree this term reduces to $-36.4 \mathrm{~W} \mathrm{~m}^{-2}$ at the centre-line of the canopy (this case has an extremely high leaf-area density). This highlights that when estimating the bulk variables to calculate the dimensionless parameters and cooling regimes, some consideration should be given to the changes occurring within 
a)

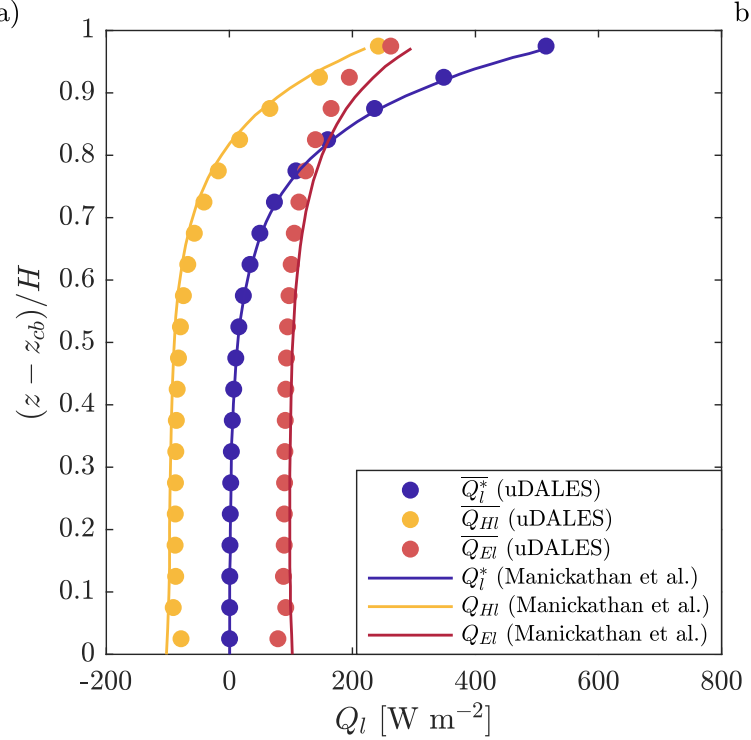

b)

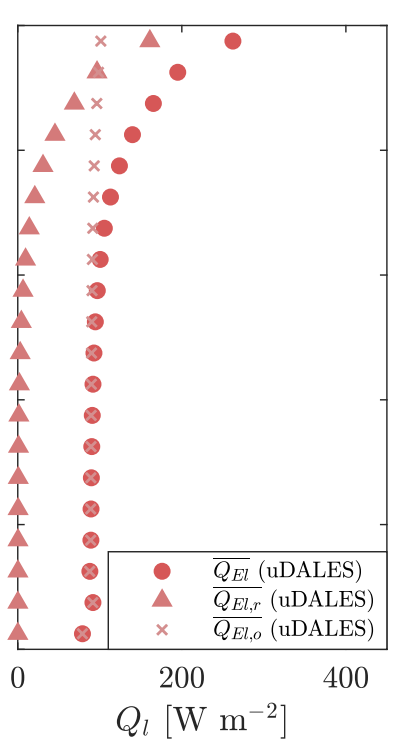

Figure 10. a) Net radiative, sensible and latent heat fluxes and b) total, advective and radiative components of the latent heat fluxes on the leaf surfaces at $x=3.5 \mathrm{~m}$ in the single-row-of-trees case. Comparison against values obtained by Manickathan et al. (2018).

the tree. The shading effect is neglected from the study of Manickathan et al. (2018) so the cooling regimes are not considered here.

\subsection{Full- and half-canopy comparison}

In this section, both the full- and half-canopy (Figure 7a and b) set-ups are simulated under non-neutral conditions. These simulations allow a comparison to be drawn against the previous studies of Shaw and Schumann (1992) and Xie and $\mathrm{Li}$ (2005) and present a new dataset that can be used in future validations.

\subsubsection{Previous studies}

Shaw and Schumann (1992) incorporated thermal effects into their full-canopy investigation by introducing a volumetric source term, $S_{T}$, as a function of the the divergence of net radiation through the tree canopy. This methodology is equivalent to neglecting the latent heat flux and any ground heat flux in the tree model. Xie and Li (2005) developed upon this study by investigating the half-canopy simulation set-up displayed in Figure 7b. Two cases were considered in the investigation of Xie and $\mathrm{Li}$ (2005). The first case followed the same set of assumptions as Shaw and Schumann (1992) in defining constant volumetric heat sources throughout the tree canopy. This set-up aimed to reproduce strong radiative conditions where the divergence of radiation through the canopy leads to elevated sources of temperature. The second case reversed the sign of the volumetric source terms such that the tree canopies act to cool the surrounding air (this set-up aimed to reproduce weak radiative conditions where transpirational cooling dominates). With this simplified approach, reasonable agreement was obtained between the LES results of Xie and Li (2005) and the field study of Gao et al. (1989).

\subsubsection{Simulation set-up}

The tree model presented in this article provides the capability to reconsider these full- and half-canopy simulation set-ups, this time with a full energy balance model. Two simulations are performed to this end in this study, one with a full-canopy (FC; Figure 7a) and one with a half-canopy (HC; Figure 7b) set-up.

The domain size for both simulations is $192 \times 192 \times 96 \mathrm{~m}$ with a resolution of $1 \mathrm{~m}$ in all directions. The boundary conditions for momentum, flow forcing and tree canopy properties are the same as the case discussed in Section 5.1. Non-neutral conditions were modelled in these simulations with periodic boundary conditions applied for potential 
a) $\langle\bar{u}\rangle_{y}[\mathrm{~m} / \mathrm{s}]$

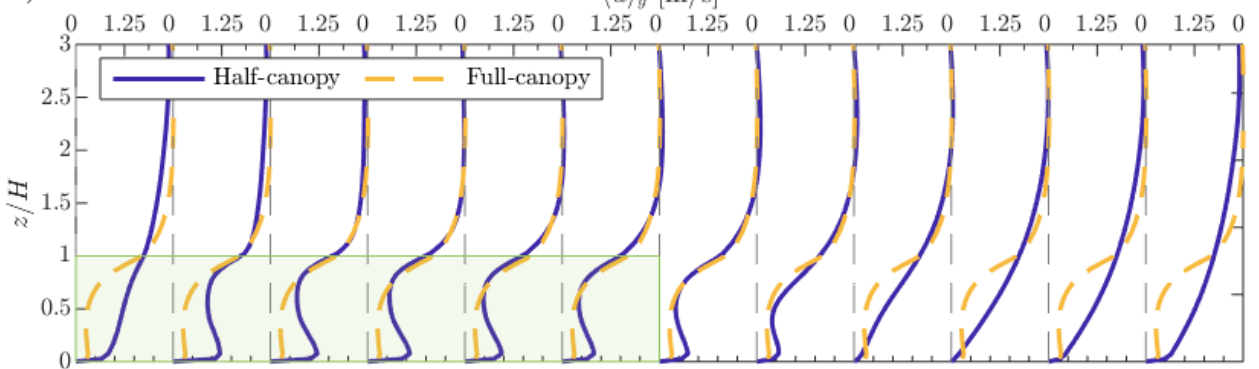

b)

$\langle\bar{\theta}\rangle_{y}-\theta(z=80 \mathrm{~m})[\mathrm{K}]$
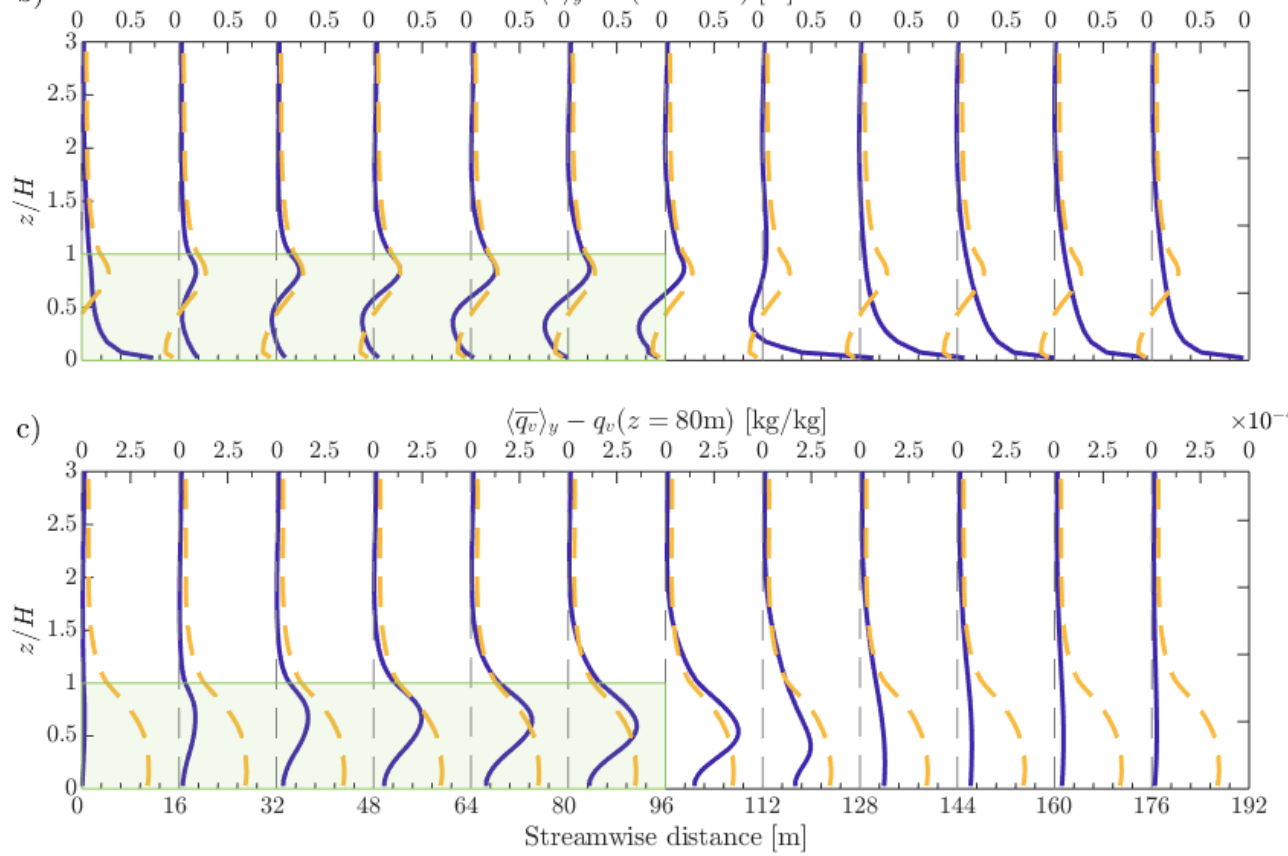

Figure 11. Spanwise and time averaged a) streamwise velocity, b) potential temperature and c) water vapour specific humidity for both the halfand full-canopy simulations. The shaded green area indicates the spatial extent of the tree canopy in the half-canopy simulation.

temperature and specific humidity. Uniform initial profiles of $\theta=288 \mathrm{~K}$ and $q_{v}=0.007 \mathrm{~kg} \mathrm{~kg}^{-1}$ are defined (relative humidity of $67 \%$ ). The bottom boundary condition for temperature is set following Section 2.4 and a steady state is enforced by assigning constant values of $\theta(h)=288 \mathrm{~K}$ and $q_{v}(h)=0.007 \mathrm{~kg} \mathrm{~kg}^{-1}$ at the domain top (therefore following a surface layer assumption with uniform turbulent temperature and moisture flux profiles once the flow is fully developed; Grylls et al., 2020). Following Xie et al. (2003), the net radiation $Q_{a}^{*}=256 \mathrm{~W} \mathrm{~m}^{-2}\left(\mathrm{~d} Q_{a}^{*} / \mathrm{d} t=0 \mathrm{~W}\right.$ $\mathrm{m}^{-2} \mathrm{~h}^{-1}$ for consistency) and the extinction coefficient $\alpha=0.6$. The leaf size $l=0.15 \mathrm{~m}$ and the stomatal resistance $r_{s}=200 \mathrm{~s} \mathrm{~m}^{-1}$. Both simulations were run up for a period of 14400 seconds before averaging was done for a period of 7200 seconds with a sampling time of 2 seconds.

\subsubsection{Results}

Figure 11 displays the vertical profiles of time and spanwise averaged streamwise velocity, potential temperature and water vapour specific humidity for both simulations. Due to the streamwise homogeneity of the full-canopy simulation, the profiles are uniform in the $x$-direction. The velocity profile has a similar shape as in the full-canopy case in absence of convection (Figure 8). The main difference is that the convective nature of the flow results in 
enhanced vertical mixing above the tree canopy.

The half-canopy simulation is inhomogeneous in the streamwise direction. The drag imposed from the tree acts to reduce the wind speed below $z=H$. Towards the end of the tree canopy $(x=96 \mathrm{~m})$, the velocity profile approaches that of the full-canopy simulation. Without the presence of the tree canopy, the velocity profile tends towards a logarithmic profile over the latter half of the domain. The flow speeds up and approaches a near-logarithmic profile towards the end of the domain. The velocity profiles are in good agreement with those of Xie and $\mathrm{Li}$ (2005).

The profiles of potential temperature and specific humidity form as a result of the tree model's energy balance. In the full-canopy case, it is evident that the tree has a net warming effect in the top layer of the tree canopy $\left(Q_{H l}>0\right.$ for $z>0.5 H)$. Over this region, the net radiative flux incident on the leaves of the canopy exceeds the latent heat flux (which is a function of both this radiative flux and the vapour pressure deficit; $\hat{Q}_{H l}>0$ ). The attenuation of radiation down through the tree canopy is such that below this height $Q_{H l}$ is reduced and transpirational cooling becomes the dominant effect meaning that the air becomes cooled by the canopy $\left(\Gamma_{E}\right.$ increases and $\left.\hat{Q}_{H l}<0\right)$. In the full-canopy case, the advective component of the latent heat flux is driven by the vertical exchange of less humid air down into the tree canopy. Figure 11c clearly shows that the specific humidity is larger over the tree canopy and quickly mixed into the flow overhead. The increased humidity within the canopy results in lower rates of transpiration (lower vapour pressure deficits $D$ ). Despite these differences the latent heat flux is dominated by the advective component as opposed to that relating to the available energy at the leaf surface. For the simple full-canopy case, a tree canopy exhibits both the heating and cooling effects that were initially investigated in Xie and Li (2005).

In the half-canopy simulation, the advection of drier air into the tree canopy is not limited to vertical exchange. The step change between the modelled unshaded urban surface and the tree canopy ( $x=0 \mathrm{~m}$; Figure 7b) leads to the advection of less humid, warmer air into the tree canopy at higher velocities (the 'oasis' effect). The latent heat flux is therefore larger than in the full canopy simulation, which is evident in the rate of change in the specific humidity in Figure 11c up to $x=96 \mathrm{~m}$. As the humidity rises along the streamwise direction through the tree canopy, the magnitude of the leading edge 'oasis' effect diminishes and towards the end of the canopy $(x \approx 80 \mathrm{~m})$ the energy balance approaches that of the full canopy simulation. The temperature of the incoming air to the tree canopy is relatively increased (in comparison to simulation FC) due to the sensible heat flux from the unshaded surface. The larger latent heat flux however leads directly to larger cooling of the air in the lower layers of the tree canopy. The air is quickly cooled in the streamwise direction within the tree canopy and is cooler than the full canopy simulation at $x=96 \mathrm{~m}$. Despite the increased latent heat flux within the half-canopy simulation, the top of the tree canopy (that receives the most radiative energy) still acts to warm the surrounding air. But the tree layer over which this is the case is reduced relative to the full-canopy case $(z>0.6 H)$.

By averaging over the canopy height, the bulk leaf-area density, wind speed, temperature and humidity can be obtained to identify the cooling regimes of these trees. In the full-canopy case, the resultant NTC and TCR are constant across the length of the domain at 0.30 and -0.69 respectively. The full canopy case therefore lies within the net reduction, shading dominated regime. For the half-canopy case, these coefficients vary as the wind speed, temperature and humidity change across the breadth of the canopy. At $x=0 \mathrm{~m}, N T C=1.09$ and $T C R=0.15$ and therefore the leading edge of the canopy results in a net cooling of the air due to the relatively increased level of transpiration. Despite this increase, it suggests that shading is still the dominant mechanism of cooling. At $x=96$ $\mathrm{m}, N T C=0.49$ and $T C R=-0.48$, which agrees with the above discussion in showing that towards the end of the canopy the energy balance approaches that of the full canopy case.

The tree model also enables a breakdown of the radiative and advective components of the latent heat flux. For the full-canopy case, the ratio $\Gamma_{E}=\left\langle Q_{E l, o}\right\rangle /\left\langle Q_{E l, r}\right\rangle=2.9$ whereas at the leading edge $(x=0 \mathrm{~m})$ of the half-canopy case $\Gamma_{E}=6.5$. As expected, the advective component is the dominant mechanism for transpiration in tree canopies. However the radiative component is non-negligible and this ratio will change under different conditions as well as at the 'grey-scale' within canopies.

This simple simulation set-up indicates that 1 ) the sensible heat flux can vary significantly within canopies (particularly due to the differences between sunlit and shaded leaves), 2) the importance of accurately capturing the dynamics of the air that is mixed into a tree canopy and the mechanisms through which this happens (e.g. horizontal advection and vertical mixing) and 3) that the dimensionless analysis and cooling regimes are able to provide useful insight into complex cases. 


\section{Conclusion}

Trees are an integral part of the urban form and their presence within the urban canopy layer affects the transfer of momentum, radiation, temperature, moisture and pollutants. Yet our understanding of and ability to quantify e.g. the cooling potential of trees remains limited, key examples of which are: 1) the lack of generalised regimes and dimensionless parameters to represent tree effects; and 2) the modelling capabilities to effectively capture the complex interactions between trees and their local environments.

A tree model has been presented through which the integrated effects of trees within the urban environment (drag, transpiration, shading and deposition) can be modelled at a 'grey-scale'. The model is devised so that the number of additional free parameters is minimised and idealised, systematic studies can be conducted (working alongside the application of a simplified constant heat flux boundary condition). The tree model resolves the latent and sensible heat fluxes from the tree canopy without using a model for the leaf temperature by applying the Penman transformation. The latent heat flux is decomposed into an advective and radiative term following an adapted form of the decoupled Penman-Monteith equation. Tree shading is captured via the attenuation of net radiation down through the canopy and by modelling the heat storage at the urban surfaces using the objective hysteresis model.

An analytical investigation was carried out in order to improve our understanding of trees' cooling mechanisms and to identify regimes of tree cooling. The normalised sensible heat flux from a volume of leaves is shown to be a function of two dimensionless parameters. This term can therefore be defined by a two-dimensional parameter space that is applicable to any tree under any conditions. Bulk environmental and tree parameters were inferred from a range of field studies and were projected onto the two-dimensional parameter space (Figure 3) illustrating key differences in transpirational cooling between the different studies. Extension of the analysis to the combined surface and tree canopy energy balance system demonstrated that the net thermal effect of trees is determined by four dimensionless parameters. By introducing the net tree cooling $(N T C)$ and tree cooling ratio $(T C R)$ coefficients, the thermal effects of a tree could be categorised in five different regimes: net heating, net reduction (shading dominated), net reduction (transpiration dominated), net cooling (shading dominated) and net cooling (transpiration dominated).

A key strength of the analysis is that it enables the understanding of the sensitivity of the canopy energy balance system to various parameters. For example, the parameterisation of Gromke et al. (2015) was assessed by applying a change in leaf-area density to the relevant case study, resulting in the same relationship $\left(250 \mathrm{~W} \mathrm{~m}^{-2}\right.$ per unit leaf-area density) as in their study. However, this linear relationship only holds in the net-cooling, transpiration-dominated regime. If other parameters in this case study are changed (e.g. humidity or stomatal resistance) this relationship will change in magnitude and will not be linear for low leaf-area densities.

The application of the tree model in uDALES was validated against existing tree canopy simulations. Full-canopy, half-canopy and single row of tree simulations were conducted that validated the applied drag and energy balance model within uDALES. For the range of conditions studied, the tree canopies were shown to act as both sources and sinks of temperature, with the sensible heat flux predominantly varying over the height of the modelled canopy. The 'oasis' effect in which enhanced rates of transpiration and subsequently cooling occur was illustrated in the halfcanopy simulation. The full-canopy and half-canopy simulations present extensive and repeatable set-ups that could be applied for future model validations .

This work provides the basis for future studies that can apply the tree model to develop our understanding of the effects of trees on air quality and the UHI effect. Simulations of idealised and realistic morphologies and tree canopies under both neutral and convective conditions using computational fluid dynamics will provide vital information towards better understanding the role of trees within cities, and will form the subject of a follow-up study. Alongside this, the identified dimensionless parameters can be used in field, experimental and computational studies to contextualise the cooling mechanism of different trees and under different scenarios. Combined, the tools presented in this paper open up the possibility for a wealth of further work on urban trees.

The tree model presented here can be easily extended with more detailed physics (at the price of extra parameters). These are, for example, the resuspension of pollutants and the emission of volatile organic compounds from tree canopies. Furthermore, one could extend the radiative model to capture short- and longwave radiative exchanges independently and to incorporate these within a three-dimensional urban energy balance model. 


\section{Acknowledgments}

The input of MEng student Niruthavignesh Sundararajah contributed to our initial understanding of the subject area. T.G. would like to acknowledge support by the EPSRC Centre for Doctoral Training in Sustainable Civil Engineering (grant reference EP/L016826/1). The computational resources for this work were provided by the Imperial College HPC facilities and the UK National Supercomputing Service, ARCHER, through resources provided by the UK Turbulence Consortium (grant number EP/R029326/1).

\section{Appendix A. Tree canopy Penman-Monteith derivation}

The equations for the latent and sensible heat fluxes between a leaf and the surrounding air were established in Section 2.3, and are given by

$$
\begin{aligned}
Q_{H l} & =\frac{2}{r_{a}} \rho c_{p}\left(T_{l}-T\right), \\
Q_{E l} & =\frac{1}{r_{a}+r_{s}} \frac{\rho R_{a} L_{v}}{p_{0} R_{v}}\left(\varepsilon_{v l}-\varepsilon_{v}\right),
\end{aligned}
$$

where the right-hand sides of the equations are composed of resistance terms for the pathway between the leaf surface and bulk air ( $r_{s}$ is the stomatal resistance and $r_{a}$ is the aerodynamic resistance), unit conversion terms ( $\rho$ is the density of air, $c_{p}$ is the heat capacity of the air, $R_{a}$ and $R_{v}$ are the gas constants of dry air and water vapour respectively, $p_{0}$ is the atmospheric pressure and $L_{v}$ is the latent heat of vaporisation) and finally a vapour pressure, $\varepsilon$, or temperature difference (leaf temperature, $T_{l}$, and air temperature, $T$ ).

The vapour pressure at the leaf surface is at saturation point and therefore $\varepsilon_{v l}=\varepsilon_{s}\left(T_{l}\right)$ where $\varepsilon_{s}$ is the saturation vapour pressure. Both Equations A.1 and A.2 are therefore a function of the leaf temperature. It is possible to avoid the need to model the leaf temperature by following the Penman transformation (Penman, 1948). The first step is to partition the surface-air vapour pressure deficit into two terms (using a Taylor series expansion of $\varepsilon_{s}\left(T_{l}\right)$ around the air temperature $T$; Jones, 2013)

$$
\varepsilon_{s}\left(T_{l}\right)-\varepsilon_{v}=\left[\varepsilon_{s}(T)-\varepsilon_{v}\right]+\left[\varepsilon_{s}\left(T_{l}\right)-\varepsilon_{s}(T)\right]=D+s\left(T_{l}-T\right)
$$

where $s=\partial \varepsilon_{s} /\left.\partial T\right|_{T}$ is the slope of the curve relating saturation vapour pressure to temperature at the air temperature $T ; D$ is the vapour pressure deficit of the ambient air. It is assumed that $s$ is approximately constant over the defined range of temperatures.

Substituting Equation A.3 into Equation A.2 gives

$$
Q_{E l}=\frac{1}{r_{a}+r_{s}} \frac{\rho R_{a} L_{v}}{p_{0} R_{v}}\left[D+s\left(T_{l}-T\right)\right] .
$$

Now both the latent and sensible heat fluxes can be defined as a function of the leaf-air temperature difference $\left(T_{l}-T\right)$ (Equations A.1 and A.4). Rearranging Equation A.1 for $\left(T_{l}-T\right)$ and substituting into Equation A.4 then gives

$$
Q_{E l}=\frac{1}{r_{a}+r_{s}} \frac{\rho R_{a} L_{v}}{p_{0} R_{v}}\left[D+\frac{s Q_{H l}}{\frac{2}{r_{a}} \rho c_{p}}\right] .
$$

$Q_{H l}$ can be defined by rearranging the leaf energy balance equation (Equation 10)

$$
Q_{H l}=Q_{l}^{*}-Q_{E l} .
$$

Substituting this relation into Equation A.5 and rearranging gives

$$
Q_{E l}=\frac{s Q_{l}^{*}+\frac{2}{r_{a}} \rho c_{p} D}{s+2 \gamma \frac{\left(r_{a}+r_{s}\right)}{r_{a}}}
$$


${ }_{638} \hat{Q}_{c}^{*} \quad$ Proportion of net radiation absorbed by the tree (-)

${ }_{639} \hat{Q}_{e} \quad$ Dimensionless transpirational cooling term (-)

${ }_{640} \hat{Q}_{H 0} \quad$ Dimensionless ground sensible heat flux (-)

${ }_{641} \omega_{l} \quad$ Dimensionless decoupling parameter (-)

${ }_{642} \phi_{\theta} \quad$ Temperature flux $\left(\mathrm{K} \mathrm{m} \mathrm{s}^{-1}\right)$

${ }_{643} \rho \quad$ Density of air $\left(\mathrm{kg} \mathrm{m}^{-3}\right)$

${ }_{644} \theta \quad$ Potential temperature (K)

${ }_{645} \varphi \quad$ Pollution concentration $\left(\mathrm{kg} \mathrm{m}^{-3}\right)$

${ }_{646} a$ leaf-area density $\left(\mathrm{m}^{2} \mathrm{~m}^{-3}\right)$

${ }_{647} \quad C_{d} \quad$ Drag coefficient (-)

${ }_{648} \quad c_{p} \quad$ Heat capacity $\left(\mathrm{J} \mathrm{K}^{-1}\right)$

${ }_{649} D \quad$ Vapour pressure deficit $(\mathrm{Pa})$

${ }_{650} d \quad$ Leaf area index (-)

$651 \quad H \quad$ Tree height $(\mathrm{m})$

$$
\varepsilon_{s}=610.8 \exp \left(\frac{17.27(T-273.15)}{T-35.85}\right) .
$$

$$
s=\frac{4098 \varepsilon_{s}}{(T-35.85)^{2}} .
$$

27




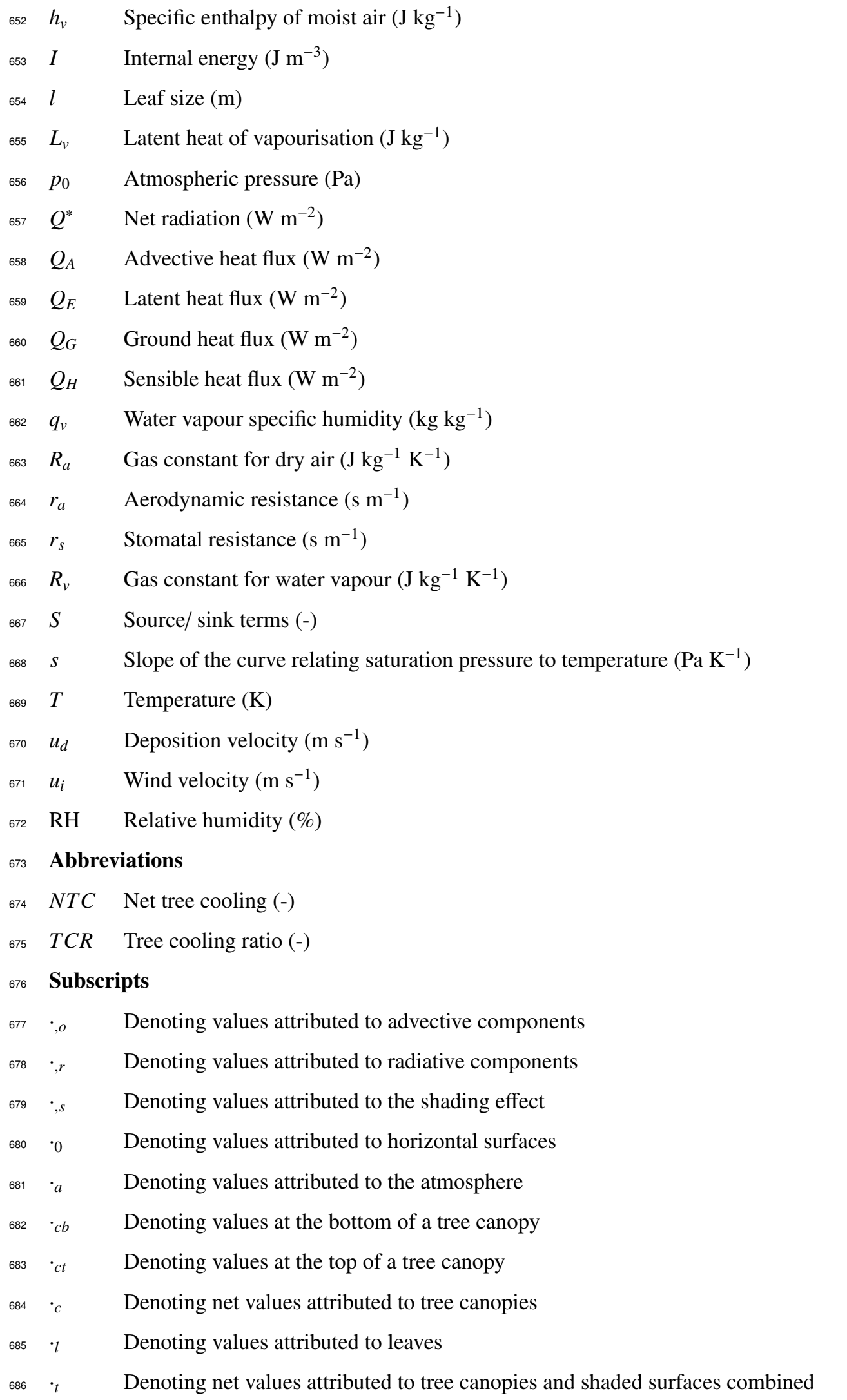




\section{References}

Abhijith, K., Kumar, P., Gallagher, J., McNabola, A., Baldauf, R., Pilla, F., Broderick, B., Di Sabatino, S., Pulvirenti, B., 2017. Air pollution abatement performances of green infrastructure in open road and built-up street canyon environments-a review. Atmospheric Environment 162, 71-86.

Akbari, H., Rosenfeld, A.H., Taha, H., 1990. Summer heat islands, urban trees, and white surfaces, in: Proceedings of the 1990 ASHRAE Winter Conference, p. 1381.

Barradas, V.L., 2000. Energy balance and transpiration in an urban tree hedgerow in mexico city. Urban Ecosystems 4, 55-67.

Bertoldi, G., Kustas, W.P., Albertson, J.D., 2013. Evaluating source area contributions from aircraft flux measurements over heterogeneous land using large-eddy simulation. Boundary-layer meteorology 147, 261-279.

Bittelli, M., Ventura, F., Campbell, G.S., Snyder, R.L., Gallegati, F., Pisa, P.R., 2008. Coupling of heat, water vapor, and liquid water fluxes to compute evaporation in bare soils. Journal of Hydrology 362, 191-205.

Boppana, V.B.L., Xie, Z.T., Castro, I.P., 2014. Thermal Stratification Effects on Flow Over a Generic Urban Canopy. Boundary-Layer Meteorology $153,141-162$

Bowler, D.E., Buyung-Ali, L., Knight, T.M., Pullin, A.S., 2010. Urban greening to cool towns and cities: A systematic review of the empirical evidence. Landscape and urban planning 97, 147-155.

Bozovic, R., Maksimovic, C., Mijic, A., Smith, K.M., Suter, I., Van Reeuwijk, M., 2017. Blue Green Solutions. A Systems Approach to Sustainable and Cost-Effective Urban Development. Technical Report. Climate KIC.

Brown, K.W., Covey, W., 1966. The energy-budget evaluation of the micrometeorological transfer processes within a cornfield. Agricultural Meteorology 3, 73-96.

Buccolieri, R., Santiago, J.L., Rivas, E., Sanchez, B., 2018. Review on urban tree modelling in cfd simulations: Aerodynamic, deposition and thermal effects. Urban Forestry \& Urban Greening 31, 212-220.

Buck, A.L., 1981. New equations for computing vapor pressure and enhancement factor. Journal of applied meteorology 20, 1527-1532.

Chen, X., Zhao, P., Hu, Y., Ouyang, L., Zhu, L., Ni, G., 2019. Canopy transpiration and its cooling effect of three urban tree species in a subtropical city-guangzhou, china. Urban Forestry \& Urban Greening 43, 126368.

Cionco, R.M., 1979. A summary of an analysis of canopy flow coupling for a variety of canopy types, in: Preprint volume, In: 14th Conference of the American Meteorological Society, on Agriculture and Forest Meteorology, Minneapolis, Minnesota, pp. $105-106$.

Dai, Y., Dickinson, R.E., Wang, Y.P., 2004. A two-big-leaf model for canopy temperature, photosynthesis, and stomatal conductance. Journal of Climate 17, 2281-2299.

Damour, G., Simonneau, T., Cochard, H., Urban, L., 2010. An overview of models of stomatal conductance at the leaf level. Plant, Cell \& Environment 33, 1419-1438.

Dauzat, J., Rapidel, B., Berger, A., 2001. Simulation of leaf transpiration and sap flow in virtual plants: model description and application to a coffee plantation in costa rica. Agricultural and forest meteorology 109, 143-160.

Donovan, G.H., 2017. Including public-health benefits of trees in urban-forestry decision making. Urban forestry \& urban greening 22, 120-123.

Emanuel, K.A., 1994. Atmospheric convection. Oxford University Press on Demand

Gao, W., Shaw, R.H., et al., 1989. Observation of organized structure in turbulent flow within and above a forest canopy, in: Boundary Layer Studies and Applications. Springer, pp. 349-377.

Grey, G.W., Deneke, F.J., et al., 1978. Urban forestry. John Wiley and Sons.

Grimmond, C.S.B., Oke, T.R., 1991. An evapotranspiration-interception model for urban areas. Water Resources Research 27, 1739-1755.

Grimmond, C.S.B., Oke, T.R., 1999. Heat storage in urban areas: Local-scale observations and evaluation of a simple model. Journal of applied meteorology 38, 922-940.

Grimmond, C.S.B., Oke, T.R., 2002. Turbulent heat fluxes in urban areas: Observations and a local-scale urban meteorological parameterization scheme (lumps). Journal of Applied Meteorology 41, 792-810.

Gromke, C., Blocken, B., Janssen, W., Merema, B., van Hooff, T., Timmermans, H., 2015. Cfd analysis of transpirational cooling by vegetation: Case study for specific meteorological conditions during a heat wave in arnhem, netherlands. Building and Environment 83, 11-26.

Gromke, C., Buccolieri, R., Di Sabatino, S., Ruck, B., 2008. Dispersion study in a street canyon with tree planting by means of wind tunnel and numerical investigations-evaluation of cfd data with experimental data. Atmospheric Environment 42, 8640-8650.

Gromke, C., Ruck, B., 2007. Influence of trees on the dispersion of pollutants in an urban street canyon-experimental investigation of the flow and concentration field. Atmospheric Environment 41, 3287-3302.

Gromke, C., Ruck, B., 2009. On the impact of trees on dispersion processes of traffic emissions in street canyons. Boundary-Layer Meteorology $131,19-34$

Grylls, T., 2020. Simulating air pollution in the urban microclimate. Ph.D. thesis. Imperial College London.

Grylls, T., Ivo, S., van Reeuwijk, M., 2020. Steady-state large-eddy simulations of convective and stable urban boundary layers. Boundary Layer Meteorology 175, 309-341.

Grylls, T., Le Cornec, C.M., Salizzoni, P., Soulhac, L., Stettler, M.E.J., van Reeuwijk, M., 2019. Evaluation of an operational air quality model using large-eddy simulation. Atmospheric Environment: X 3, 100041.

Gu, Z., Zhang, Y., Lei, K., 2010. Large eddy simulation of flow in a street canyon with tree planting under various atmospheric instability conditions. Science China Technological Sciences 53, 1928-1937.

Heus, T., Vilà-Guerau de Arellano, J., De Roode, S., Pino González, D., Van Heerwaarden, C.C., Jonker, H.J.J., Siebesma, P., Axelsen, S., Van den Dries, K., Geoffroy, O., et al., 2010. Formulation of the dutch atmospheric large-eddy simulation (dales) and overview of its applications. Geoscientific Model Development 3, 415-444.

Holtslag, A.A.M., Nieuwstadt, F.T.M., 1986. Scaling the atmospheric boundary layer. Boundary-Layer Meteorology 36, 201-209.

Huttner, S., 2012. Further development and application of the 3d microclimate simulation envi-met. Mainz University, Germany .

Janhäll, S., 2015. Review on urban vegetation and particle air pollution-deposition and dispersion. Atmospheric environment 105, $130-137$. 
Jeanjean, A.P., Buccolieri, R., Eddy, J., Monks, P.S., Leigh, R.J., 2017. Air quality affected by trees in real street canyons: The case of marylebone neighbourhood in central london. Urban Forestry \& Urban Greening 22, 41-53.

Jones, H.G., 2013. Plants and microclimate: a quantitative approach to environmental plant physiology. Cambridge university press.

Kasten, F., Czeplak, G., 1980. Solar and terrestrial radiation dependent on the amount and type of cloud. Solar energy 24, 177-189.

Konarska, J., Uddling, J., Holmer, B., Lutz, M., Lindberg, F., Pleijel, H., Thorsson, S., 2016. Transpiration of urban trees and its cooling effect in a high latitude city. International journal of biometeorology 60, 159-172.

Li, Q., Wang, Z.H., 2018. Large-eddy simulation of the impact of urban trees on momentum and heat fluxes. Agricultural and Forest Meteorology 255, 44-56.

Lindén, J., Fonti, P., Esper, J., 2016. Temporal variations in microclimate cooling induced by urban trees in mainz, germany. Urban Forestry \& Urban Greening 20, 198-209.

Machimura, T., Nakai, T., Okada, K., Tanaka, Y., Urano, S., Horiguchi, I., 1997. Comparison of evapotransiration variation among different vegetative canopies using 'decoupling'theory. Journal of Agricultural Meteorology 52, 497-500.

Manickathan, L., Defraeye, T., Allegrini, J., Derome, D., Carmeliet, J., 2018. Parametric study of the influence of environmental factors and tree properties on the transpirative cooling effect of trees. Agricultural and forest meteorology 248, 259-274.

Matsuda, K., Onishi, R., Takahashi, K., 2018. Tree-crown-resolving large-eddy simulation coupled with three-dimensional radiative transfer model. Journal of Wind Engineering and Industrial Aerodynamics 173, 53-66.

McHugh, C., Carruthers, D., Edmunds, H., 1997. Adms and adms-urban. International Journal of Environment and Pollution 8, $438-440$.

McNaughton, K.G., Jarvis, P.G., 1983. Predicting effects of vegetation changes on transpiration and evaporation. Water deficits and plant growth $7,1-47$.

Monteith, J., Unsworth, M., 2013. Principles of environmental physics: plants, animals, and the atmosphere. Academic Press.

Moonen, P., Gromke, C., Dorer, V., 2013. Performance assessment of large eddy simulation (les) for modeling dispersion in an urban street canyon with tree planting. Atmospheric environment 75, 66-76.

Moradpour, M., Afshin, H., Farhanieh, B., 2017. A numerical investigation of reactive air pollutant dispersion in urban street canyons with tree planting. Atmospheric Pollution Research 8, 253-266.

Morakinyo, T.E., Kong, L., Lau, K.K.L., Yuan, C., Ng, E., 2017. A study on the impact of shadow-cast and tree species on in-canyon and neighborhood's thermal comfort. Building and Environment 115, 1-17.

Mullaney, J., Lucke, T., Trueman, S.J., 2015. A review of benefits and challenges in growing street trees in paved urban environments. Landscape and Urban Planning 134, 157-166.

Oke, T.R., 1982. The energetic basis of the urban heat island. Quarterly Journal of the Royal Meteorological Society 108, 1-24.

Oke, T.R., 1989. The micrometeorology of the urban forest. Philosophical Transactions of the Royal Society of London. B, Biological Sciences 324, 335-349.

Oke, T.R., Mills, G., Christen, A., Voogt, J.A., 2017. Urban climates. Cambridge University Press.

Oliphant, A.J., Grimmond, C.S.B., Zutter, H.N., Schmid, H.P., Su, H.B., Scott, S.L., Offerle, B.J.C.R., Randolph, J.C., Ehman, J., 2004. Heat storage and energy balance fluxes for a temperate deciduous forest. Agricultural and Forest Meteorology 126, 185-201.

Oshio, H., Asawa, T., Hoyano, A., Miyasaka, S., 2015. Estimation of the leaf area density distribution of individual trees using high-resolution and multi-return airborne lidar data. Remote Sensing of Environment 166, 116-125.

Parlange, J.Y., Waggoner, P.E., 1972. Boundary layer resistance and temperature distribution on still and flapping leaves: Ii. field experiments. Plant Physiology 50, 60-63.

Patton, E.G., Sullivan, P.P., Shaw, R.H., Finnigan, J.J., Weil, J.C., 2016. Atmospheric stability influences on coupled boundary layer and canopy turbulence. Journal of the Atmospheric Sciences 73, 1621-1647.

Penman, H.L., 1948. Natural evaporation from open water, bare soil and grass. Proceedings of the Royal Society of London. Series A. Mathematical and Physical Sciences 193, 120-145.

Pereira, A.R., 2004. The priestley-taylor parameter and the decoupling factor for estimating reference evapotranspiration. Agricultural and Forest Meteorology 125, 305-313.

Rahman, M.A., Moser, A., Rötzer, T., Pauleit, S., 2017. Microclimatic differences and their influence on transpirational cooling of tilia cordata in two contrasting street canyons in munich, germany. Agricultural and Forest Meteorology 232, 443-456.

Rahman, M.A., Moser, A., Rötzer, T., Pauleit, S., 2019. Comparing the transpirational and shading effects of two contrasting urban tree species. Urban Ecosystems , 1-15.

Rahman, M.A., Stratopoulos, L.M., Moser-Reischl, A., Zölch, T., Häberle, K.H., Rötzer, T., Pretzsch, H., Pauleit, S., 2020. Traits of trees for cooling urban heat islands: A meta-analysis. Building and Environment 170, 106606.

Robitu, M., Musy, M., Inard, C., Groleau, D., 2006. Modeling the influence of vegetation and water pond on urban microclimate. Solar energy 80, 435-447.

Rowntree, R.A., 1984. Ecology of the urban forest-introduction to part i. Urban Ecology 8, 1-11.

Saaroni, H., Amorim, J.H., Hiemstra, J.A., Pearlmutter, D., 2018. Urban green infrastructure as a tool for urban heat mitigation: Survey of research methodologies and findings across different climatic regions. Urban climate 24, 94-110.

Sæbø, A., Popek, R., Nawrot, B., Hanslin, H.M., Gawronska, H., Gawronski, S.W., 2012. Plant species differences in particulate matter accumulation on leaf surfaces. Science of the Total Environment 427, 347-354.

Salim, M.H., Schlünzen, K.H., Grawe, D., 2015. Including trees in the numerical simulations of the wind flow in urban areas: should we care? Journal of Wind Engineering and Industrial Aerodynamics 144, 84-95.

Salim, M.H., Schlünzen, K.H., Grawe, D., Boettcher, M., Gierisch, A.M., Fock, B.H., 2018. The microscale obstacle-resolving meteorological model mitras v2. 0: model theory. Geoscientific Model Development 11, 3427-3445.

Santiago, J.L., Martilli, A., Martin, F., 2017. On dry deposition modelling of atmospheric pollutants on vegetation at the microscale: Application to the impact of street vegetation on air quality. Boundary-layer meteorology 162, 451-474.

Shashua-Bar, L., Pearlmutter, D., Erell, E., 2009. The cooling efficiency of urban landscape strategies in a hot dry climate. Landscape and Urban Planning 92, 179-186 
Shaw, R.H., Schumann, U., 1992. Large-eddy simulation of turbulent flow above and within a forest. Boundary-Layer Meteorology 61, 47-64.

Smithers, R.J., Doick, K.J., Burton, A., Sibille, R., Steinbach, D., Harris, R., Groves, L., Blicharska, M., 2018. Comparing the relative abilities of tree species to cool the urban environment. Urban ecosystems 21, 851-862.

Soulhac, L., Salizzoni, P., Cierco, F.X., Perkins, R., 2011. The model SIRANE for atmospheric urban pollutant dispersion; PART I, Presentation of the model. Atmospheric Environment 45, 7379-7395.

Sun, T., Wang, Z.H., Oechel, W., Grimmond, S., 2017. The analytical objective hysteresis model (anohm v1. 0): methodology to determine bulk storage heat flux coefficients. Geoscientific Model Development 10, 2875-2890.

Suter, I., 2018. Simulating the impact of blue-green infrastructure on the microclimate of urban areas. Ph.D. thesis. Imperial College London.

Suter, I., Grylls, T., Sützl, B., van Reeuwijk, M., 2020. udales: a large-eddy-simulation model for urban environments [in preparation]. Geoscientific Model Development

Tan, P.Y., Wong, N.H., Tan, C.L., Jusuf, S.K., Chang, M.F., Chiam, Z.Q., 2018. A method to partition the relative effects of evaporative cooling and shading on air temperature within vegetation canopy. Journal of Urban Ecology 4, juy012.

Tan, Z., Lau, K.K.L., Ng, E., 2016. Urban tree design approaches for mitigating daytime urban heat island effects in a high-density urban environment. Energy and Buildings 114, 265-274.

Thom, A.S., 1968. The exchange of momentum, mass, and heat between an artificial leaf and the airflow in a wind-tunnel. Quarterly Journal of the Royal Meteorological Society 94, 44-55.

Tomas, J.M., Pourquie, M.J.B.M., Jonker, H.J.J., 2015. The influence of an obstacle on flow and pollutant dispersion in neutral and stable boundary layers. Atmospheric Environment 113, 236-246.

Uno, I., Wakamatsu, S., Ueda, H., Nakamura, A., 1988. An observational study of the structure of the nocturnal urban boundary layer. BoundaryLayer Meteorology 45, 59-82.

Vreman, A.W., 2004. An eddy-viscosity subgrid-scale model for turbulent shear flow: Algebraic theory and applications. Physics of fluids 16, 3670-3681.

Wang, C., Wang, Z.H., Yang, J., 2018. Cooling effect of urban trees on the built environment of contiguous united states. Earth's Future 6, 1066-1081.

Wang, Y., Akbari, H., 2016. The effects of street tree planting on urban heat island mitigation in montreal. Sustainable cities and society 27, $122-128$.

Willis, K.J., Petrokofsky, G., 2017. The natural capital of city trees. Science 356, 374-376.

Wilson, N.R., Shaw, R.H., 1977. A higher order closure model for canopy flow. Journal of Applied Meteorology 16, 1197-1205.

Xie, S., Zhang, Y., Qi, L., Tang, X., 2003. Spatial distribution of traffic-related pollutant concentrations in street canyons. Atmospheric Environment 37, 3213-3224.

Xie, Z., Li, J., 2005. A numerical study for turbulent flow and thermal influence over inhomogenous canopy of roughness elements. Environmental Fluid Mechanics 5, 577-597.

Yang, Y., Gatto, E., Gao, Z., Buccolieri, R., Morakinyo, T.E., Lan, H., 2019. The "plant evaluation model" for the assessment of the impact of vegetation on outdoor microclimate in the urban environment. Building and Environment .

Zhao, W., Qualls, R.J., 2005. A multiple-layer canopy scattering model to simulate shortwave radiation distribution within a homogeneous plant canopy. Water resources research 41 .

Zhao, W., Qualls, R.J., 2006. Modeling of long-wave and net radiation energy distribution within a homogeneous plant canopy via multiple scattering processes. Water resources research 42 . 